\title{
Article
}

\section{Operando XAS Study of Atomic Phase Reversibility with Wavelet Transform in the Lithium-rich Manganese Based Oxide Cathode}

\author{
Taehoon Kim, Bohang Song, Alexander J.G. Lunt, Giannantonio \\ Cibin, Andrew J. Dent, Li Lu, and Alexander M. Korsunsky \\ Chem. Mater., Just Accepted Manuscript • Publication Date (Web): 03 Jun 2016
}

Downloaded from http://pubs.acs.org on June 3, 2016

\section{Just Accepted}

"Just Accepted" manuscripts have been peer-reviewed and accepted for publication. They are posted online prior to technical editing, formatting for publication and author proofing. The American Chemical Society provides "Just Accepted" as a free service to the research community to expedite the dissemination of scientific material as soon as possible after acceptance. "Just Accepted" manuscripts appear in full in PDF format accompanied by an HTML abstract. "Just Accepted" manuscripts have been fully peer reviewed, but should not be considered the official version of record. They are accessible to all readers and citable by the Digital Object Identifier (DOI®). "Just Accepted" is an optional service offered to authors. Therefore, the "Just Accepted" Web site may not include all articles that will be published in the journal. After a manuscript is technically edited and formatted, it will be removed from the "Just Accepted" Web site and published as an ASAP article. Note that technical editing may introduce minor changes to the manuscript text and/or graphics which could affect content, and all legal disclaimers and ethical guidelines that apply to the journal pertain. ACS cannot be held responsible for errors or consequences arising from the use of information contained in these "Just Accepted" manuscripts. 


\section{INTRODUCTION}

Continuing interest in the sustainable use of the Li-ion batteries for electrical transportation continues to drive forward further developments in the cathode materials. Developing a high capacity cathode with good structural and chemical stability remains the principal objective of this research. Lithium-rich Mn-based composites having the chemical formula of $\mathrm{xLi}_{2} \mathrm{MnO}_{3} \cdot(1-\mathrm{x}) \mathrm{LiMO}_{2}(\mathrm{M}=\mathrm{Mn}$, $\mathrm{Co}, \mathrm{Ni}$ ) are a class of promising active materials for these applications. This cathode system benefits from high theoretical reversible capacity (over $250 \mathrm{mAh} / \mathrm{g}$ ), high operating voltage (2.0-4.7 $\mathrm{V}$ vs $\mathrm{Li}^{+} / \mathrm{Li}$ ), high discharge capacity, good inherent thermal/structural stability and lower $\operatorname{cost}^{1-7}$. However, questions have been raised about the stability during prolonged use of lithium-rich Mn-based materials because of the irreversible capacity loss of $4^{0}-$ $100 \mathrm{mAh} / \mathrm{g}$ during the first electrochemical cycle ${ }^{8-12}$. Thus, as a consequence of structural modifications during the first cycle a battery is likely to lose around one third of its capacity. Lithia $\left(\mathrm{Li}_{2} \mathrm{O}\right)$ extraction followed by the removal of the oxide ion vacancies involving the transition metals migration is known to be the dominant mechanism of irreversible capacity loss during the first cycle ${ }^{11,13-17}$. This reaction mechanism is linked to the nature of structural integration between Li-rich oxides $\mathrm{Li}_{2} \mathrm{MnO}_{3}$ (monoclinic,
$\mathrm{C}_{2} / \mathrm{m}$ ) and $\mathrm{LiMO}_{2}$ (trigonal, $\mathrm{R} \overline{3} \mathrm{~m}$ ), where $\mathrm{M}$ represents a transition metal ion (Mn, Co or Ni). The intimate integration is attributed to the interleaved structure of closepacked layers of the (ool) planes from $\mathrm{Li}_{2} \mathrm{MnO}_{3}$ and the (оо3) planes from $\mathrm{LiMO}_{2}$ with the interlayer spacing of $\sim 4.7 \AA^{1,8,18}$. The $\mathrm{LiMO}_{2}$ is likely to be electrochemically activated with the $\mathrm{Li}^{+}$(de)intercalation between $2.0 \mathrm{~V}$ and $\sim 4.4 \mathrm{~V}$, while the $\mathrm{Li}_{2} \mathrm{MnO}_{3}$ is known to be inactive as the oxidation state of $\mathrm{Mn}$ in the $\mathrm{Li}_{2} \mathrm{MnO}_{3}$ is already +4 . Therefore, the $\mathrm{Li}_{2} \mathrm{MnO}_{3}$ has been considered to play a stabilizing role in the mixed oxide cathode. However, if a $\mathrm{Li}_{2} \mathrm{MnO}_{3}$-like nano-domains appear by the excess lithium ions added to the transition metal composites containing random distributions of $\mathrm{Mn}^{4+}$, they can be electrochemically activated at higher voltages $(>4.5 \mathrm{~V})^{1,18-20}$. The activation of the $\mathrm{Li}_{2} \mathrm{MnO}_{3}$ phase leads to the increment of the electrostatic repulsion between the close-packed oxygen layers and thus increases the $c$-lattice of the $R \overline{3} \mathrm{~m}$ crystal structure (Figure 1a). Also, the presence of the $\mathrm{Li}_{2} \mathrm{MnO}_{3}$ phase is responsible for the observed voltage plateau in the galvanostatic profile from $4.4 \mathrm{~V}$ to $4.6 \mathrm{~V}$, which corresponds to the $\mathrm{Li}_{2} \mathrm{O}$ extraction taking place. As a consequence, irrespective of whether the component has composite structure, the energy level of the $\mathrm{M}^{\mathrm{n}+1} / \mathrm{M}^{\mathrm{n}}$ redox couples relative to the Fermi energy of Li will change depending upon the individual atomic environment ${ }^{2}$. It is 
therefore of great importance to characterize correctly the chemical environment of transition metal atoms (Mn, Co, and $\mathrm{Ni}$ ).

Numerous attempts have been made to improve the performance and stability of the $\mathrm{Li}\left(\mathrm{Li}_{\mathrm{O} .2} \mathrm{Mn}_{\mathrm{O} .54} \mathrm{Ni}_{\text {O.13 }} \mathrm{Co}_{0.13}\right) \mathrm{O}_{2}$ cathode by chemical and physical methods such as $\mathrm{Ru}$ doping $^{21}$, blending the cathode with spinel $\mathrm{Li}_{4} \mathrm{Mn}_{5} \mathrm{O}_{12}$ or $\mathrm{LiV}_{3} \mathrm{O}_{8}{ }^{22}$, optimizing the morphology and size of the active material by diverse synthesis methods ${ }^{23-25}$ (e.g. co-precipitation, polymer-pyrolysis, and sol-gel), and incorporating graphene in the $\mathrm{Li}\left(\mathrm{Li}_{\text {o.2 }} \mathrm{Mn}_{0.54} \mathrm{Ni}_{\text {o.13 }} \mathrm{Co}_{0.13}\right) \mathrm{O}_{2}$ cathode $^{26}$. In order to identify an optimizing treatment on the cathode composite, it is vital to understand the chemical state, local structure, and the electronic structure of the constitutive elements at the atomic scale. For this purpose, in situ X-ray absorption spectroscopy (XAS) offers a powerful method to characterize the electrochemical system of the lithiumion battery due to its capacity for simultaneous evaluation of the oxidation state as a function of the local structure change and in a highly element-specific manner ${ }^{27}$. Many studies ${ }^{28-32}$ thus far have linked the local environment and chemical state changes with electrochemical properties to elucidate key reactions and mechanisms that determine the battery performance/stability during electrochemical cycle. However, few studies have been able to draw on any systematic examination of the actual transition of the atomic phase during $\mathrm{Li}^{+}$(de)intercalation as they have been rather focused on the phase transition in the crystal structure. Although structural changes can be quantified with the Extended X-ray Absorption Fine Structure (EXAFS) at the atomic level, the information obtained (e.g. interatomic bond-length and EXAFS Debye-Waller factor) from the quantification is limited to a onedimensional function providing incomplete interpretation of the atomic environment.

Here, we report a new approach to examine in more detail the atomic state of the transition elements with the help of the Continuous Cauchy Wavelet Transform $(\mathrm{CCWT})^{33}$ analysis carried out on operando XAS data for graphene-coated $\mathrm{Li}\left(\mathrm{Li}_{\text {O.2 }} \mathrm{Mn}_{\mathrm{o} .54} \mathrm{Ni}_{\text {o.13 }} \mathrm{Co}_{0.13}\right) \mathrm{O}_{2}$ cathode. Recently, the incorporation of graphene in the Li-layered oxide cathode has emerged as an attractive treatment for lithium-ion battery materials due to the high electronic conductivity, large surface-to-volume ratio, and good chemical stability of graphene, leading to enhanced battery capacity ${ }^{26,34-38}$. Graphene is a single carbon layer materials in which the atoms hybridized in the $\mathrm{sp}^{2}$ state form hexagonal patterns. This structural property enables the effective conducting network for $\mathrm{Li}^{+}$diffusion (as high as $\left.4.4 \times 10^{-6} \mathrm{~cm}^{2} \mathrm{~s}^{-1}\right)^{39}$ and electron transport in the electrode ${ }^{34}$.

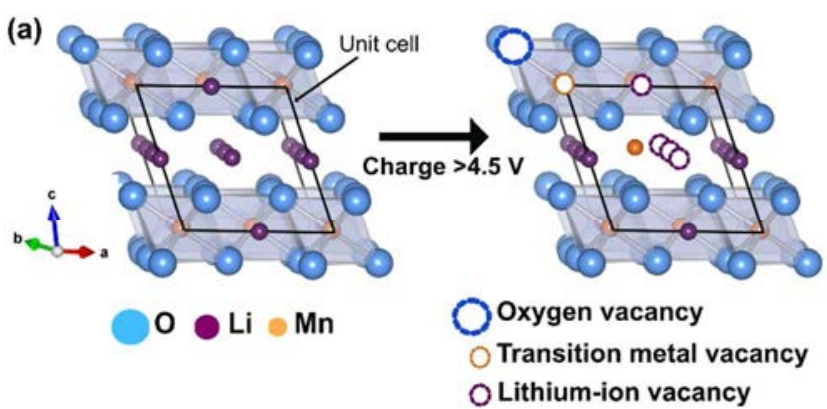

(b)

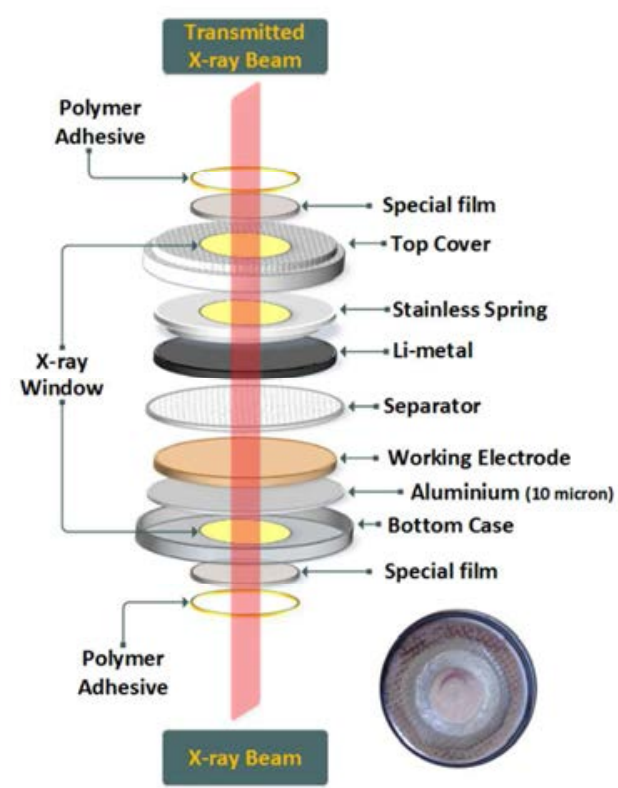

Figure 1. (a) Schematic illustration of structural changes when the cathode is exposed to voltage level higher than 4.5 $\mathrm{V}$ from $\mathrm{Li}_{2} \mathrm{MnO}_{3}$ and (b) the operando coin cell for XAS investigation.

In this study, a specially designed cell was used for the operando synchrotron XAS investigation as illustrated in Figure $1 b$. Previous studies ${ }^{4^{0-42}}$ have reported the feasible use of the cell design similar to the operando cell of the current research. Especially, the developed XAS cell is designed to improve the sealing condition preventing electrolyte leakages from the transmission X-ray window, as well as to minimize the conductivity loss due to the transmission window. Whereas manipulation can be observed in general in situ/operando cells, minimum modifications were applied to the presented XAS cell so as to reflect the actual operating environment identical to cells commercially available.

The visualization of the CCWT modulus obtained from the decomposition of the $k$-space and R-space signals from the K-edge EXAFS of Mn, Co, and Ni allowed precise characterization of the atomic environment of each transition metal in the lithium-ion battery system of the graphene-coated $\mathrm{Li}\left(\mathrm{Li}_{0.2} \mathrm{Mn}_{0.54} \mathrm{Ni}_{\text {o.13 }} \mathrm{Co}_{0.13}\right) \mathrm{O}_{2}$ cathode during the ist electrochemical cycle ( $0.5 \mathrm{C}$ rate). One of the major findings from the inspection of the results is the information about the 'atomic phase reversibility' which is difficult to obtain from one-dimensional Fourier trans- 
formed EXAFS plots that tend to emphasise the low values in the $k$-space. As a result, significant structural information linked with the multi-scattering is effectively omitted, since these processes are dominant in the signal at high $k$-value. Phase reversibility during electrochemical cycling of the battery cathode is the observable process at the crystallography level. In the current study, the reversibility has been examined with the use of wavelet transform analysis on the operando XAS that identified the changes in the local atomic environment of transition metal atoms. The current study delivers a new approach to examine the precise phase transition in the atomic environment during the ist electrochemical cycle, and thus sheds light on tailoring the electrode material for the next generation lithium-ion battery.

\section{EXPERIMENTAL SECTION}

Synthesis of active material. The active material $\mathrm{Li}\left(\mathrm{Li}_{0.2} \mathrm{Mn}_{0.54} \mathrm{Ni}_{\text {o.13 }} \mathrm{Co}_{0.13}\right) \mathrm{O}_{2}$ was synthesized by the spraydryer assisted sol-gel method. Metal acetates of $\mathrm{Mn}, \mathrm{Ni}$, and $\mathrm{Co}$ were dissolved in a $200 \mathrm{~mL}$ aqueous solution of $0.3 \mathrm{M}$ with a stoichiometry of $\mathrm{Mn}: \mathrm{Ni}: \mathrm{Co}=0.54: 0.13: 0.1$ in molar ratio. With continuous stirring, the dissolved solution was slowly introduced into a solution of $3 \%$ excess amount of lithium acetate and citric acid as a chelating agent with the same stoichiometry as the metal ions. After then, this solution was dried by a spray-dryer (YC-o15, Shanghai Politech Instrument \& Equipment Co. Ltd) and a further drying was performed on the as-sprayed precursor at $80{ }^{\circ} \mathrm{C}$ overnight. The drying was followed by the calcination at $800{ }^{\circ} \mathrm{C}$ for $15 \mathrm{~h}$ at a heating rate of $5{ }^{\circ} \mathrm{C}$ $\min ^{-1}$. The produced powders (pristine material) obtained from calcination were taken for the graphene coating after the air-cooling. The coating process was performed by a previous reported method ${ }^{36}$. $0.3 \mathrm{~g}$ of pristine material was added in $30 \mathrm{~mL}$ polyallylamine hydrochloride (PAH) with continuous stirring for $1 \mathrm{hr}$. The pristine powders were introduced in the $15 \mathrm{ml}$ graphene oxide aqueous solution $(2 \mathrm{~g} / \mathrm{L})$ with continuous stirring for another $5 \mathrm{hr}$. This solution was centrifuged and the precipitated powders were washed three times. The precipitated products were taken into L-ascorbic acid (LAA) aqueous solution at $95^{\circ} \mathrm{C}$ for $30 \mathrm{~min}$ with continuous stirring. The synthesized powder with the graphene coating was dried at 80 ${ }^{\circ} \mathrm{C}$ overnight. Finally, the graphene-coated powders were heat treated $250^{\circ} \mathrm{C}$ (or $350^{\circ} \mathrm{C}$ ) for $2 \mathrm{~h}$.

Magnetic measurement. Investigation of magnetic properties was conducted using a SQUID-VSM Magnetometer (Quantum Design). The weight of the graphenecoated active material was precisely measured by a digital scale. The measured sample was put into a small capillary, and placed into a brass stick (holder). Measurement of magnetization was carried out under a magnetic field of 1000 Oe in the temperature range of $5-300 \mathrm{~K}$. Magnetic field of 6ok Oe was applied at $5 \mathrm{~K}$ to assess the magnetic susceptibility

Preparation of the operando coin cell. A speciallydesigned coin cell, designated as CR-2025, with X-ray window was prepared to conduct the operando investigation. The electrode slurry was prepared by mixing the graphene-coated $\mathrm{Li}\left(\mathrm{Li}_{0.2} \mathrm{Mn}_{0.54} \mathrm{Ni}_{0.13} \mathrm{Co}_{0.13}\right) \mathrm{O}_{2}$ into the carbon black and polyvinylidene fluoride (PVDF) with the weight ratio of $80: 10: 10$, respectively, in the n-methyl-2pyrrolidone (NMP) solution. The coin cell with the graphene-coated $\mathrm{Li}\left(\mathrm{Li}_{0.2} \mathrm{Mn}_{0.54} \mathrm{Ni}_{0.13} \mathrm{Co}_{0.13}\right) \mathrm{O}_{2}$ electrode was labelled as 'G-type'. The electrode slurry was constantly stirred for overnight to obtain homogenous dispersion. Then, it was pasted onto an aluminium foil which was dried at $120^{\circ} \mathrm{C}$ for overnight, prior to the cutting into many pieces of working electrodes with $12 \mathrm{~mm}$ diameter. The coin cell was assembled with the working electrodes (cathode), Li-foil (anode) and two pieces of separator (Celgard 2500) in a glove box filled with argon. The electrolyte used was the organic solution of $1 \mathrm{M} \mathrm{LiPF}_{6}$ dissolved in the ethylene carbonate (EC) and diethyl carbonate (DEC) (volume ratio of EC:DEC = 1:1). The diameter and thickness of the coin cells were $20 \mathrm{~mm}$ and 2.5 $\mathrm{mm}$, respectively.

Operando XAS measurement. Synchrotron XAS was chosen for the operando investigation, and it was performed on B18 Core EXAFS beamline at Diamond Light Source (DLS, UK). Absorption spectra of Mn (6.537 keV), $\mathrm{Co}(7.712 \mathrm{keV})$, and $\mathrm{Ni}(8.339 \mathrm{keV})$ were collected at room temperature in transmission mode using a $\mathrm{Si}$ (111) double crystal monochromator. Ionization chambers were utilized to measure the intensity of incident and transmitted $\mathrm{X}$-ray beam. The size of the monochromatized beam spot on the cells was approximately $140 \mathrm{x} 140$ microns. The beam energy was initially calibrated using the reference foil spectra of $\mathrm{Mn}, \mathrm{Ni}$, and $\mathrm{Co}$. The energy was tuned to 7.1 $\mathrm{keV}, 8.225 \mathrm{keV}$, and $9.3 \mathrm{keV}$, for $\mathrm{Mn}, \mathrm{Co}$, and Ni K-edge analysis respectively. The G-type active material $(6.34 \mathrm{mg})$ was charged at a rate of $0.5 \mathrm{C}(0.634 \mathrm{~mA})$ in the voltage window of 4.8-2.o $\mathrm{V}$ vs. $\mathrm{Li}^{\circ} / \mathrm{Li}^{+}$in which the ${ }_{1} \mathrm{C}$ signifies $250 \mathrm{~mA} / \mathrm{g}$ current density. The prepared coin cell was directly clamped to the battery charger (NEWARE Battery Test Station) with wires in order to perform the operando XAS investigation.

Data interpretation for XAS and CCWT analysis. Data interpretation was performed with a IFEFFIT computation code by using the DEMETER ${ }^{43}$ software package. The EXAFS spectra were converted to frequency in $k$ space and it was weighted by $k^{3}$ to amplify the oscillations in high $\mathrm{k}$-space $\left(k^{3} \chi(k)\right)$. The distance information between coordination shells could be obtained by Fourier transform of the EXAFS oscillations into the $R$-space. Major EXAFS parameters such as the distance between the 
neighbouring shells, EXAFS Debye-Waller factor ( $\left.\exp \left(-2 \sigma^{2} k^{2}\right)\right)$, amplitude reduction factor $\left(\mathrm{S}_{\mathrm{o}}{ }^{2}\right)$, energy shift $\left(\Delta E_{0}\right)$, and the EXAFS $R$-factor were obtained by fitting within the ARTEMIS application with the FEFF 6 algorithm with atomic coordination number $(\mathrm{CN})$ of 6 for $\mathrm{Mn}$ and Co. Multiple numbers of atomic coordination (Table 3 in Supporting Information) was used for the $\mathrm{Ni}$ EXAFS fitting during the ist electrochemical cycle. After the refinement of the amplitude reduction factor $\left(\mathrm{S}_{\mathrm{o}}{ }^{2}\right)$, it was scaled to $0.7,0.67$, and 0.92 for $\mathrm{Mn}, \mathrm{Co}$, and Ni respectively. Operando XRD examinations on the $\mathrm{Li}_{1.2} \mathrm{Mn}_{0.54} \mathrm{Co}_{0.13} \mathrm{Ni}_{0.13} \mathrm{O}_{2}$ composite material has been reported elsewhere with the implication of the integrated two-phase system between $\mathrm{Li}_{2} \mathrm{MnO}_{3}$ (monoclinic, $\mathrm{C}_{2} / \mathrm{m}$ ) and $\mathrm{LiMO}_{2}$ (trigonal, $\left.\mathrm{R} \overline{3} \mathrm{~m}\right)^{8}$. Hence, EXAFS fitting was conducted using two different atomic models with the available information of crystal structure in the fitting range of 1-3.65 $\AA$ for Mn, Co, and Ni (Table 1,2,3 in Supporting Information). The Continuous Cauchy wavelet transform (CCWT) analysis was conducted on the $\mathrm{k}^{3}$ weighted normalized EXAFS data for each state of charge or depth of discharge. The Cauchy wavelet order (n) were 500,150 , and 250 for $\mathrm{Mn}, \mathrm{Co}$, and $\mathrm{Ni}$, respectively. The range of the $R$-space for the wavelet analysis was between $0.2 \AA$ and 6.o $\AA$ with the number of $R$-space intervals of 400 , which corresponds to the pixel numbers in the $R$ space.

\section{RESULTS}

Evaluation of oxidation states and magnetic properties. Normalized XANES spectra at Mn, Co, and Ni Kedge of REF (with no current applied) and last discharge point $(=\mathbf{2 . 1 8 2} \mathrm{V})$ are shown in Figure 2a,b,c. Figure 3a,b presents the magnetic susceptibility measurements for the graphene-coated $\mathrm{Li}\left(\mathrm{Li}_{0.2} \mathrm{Mn}_{0.54} \mathrm{Ni}_{0.13} \mathrm{Co}_{0.13}\right) \mathrm{O}_{2}$ in order to determine the precise oxidation states, as well as the electronic structure of the cathode material. The changes of the spectra for the remaining collection of measurement points during charge-discharge are discussed in the 'Operando XANES of Mn, Co, and Ni' section. XANES is oxidation sensitive and thus the oxidation state of a target component can be estimated by the spectra comparison between the sample and the corresponding reference composite. From the XANES result, it can be seen that there is little difference at $\mathrm{Mn}$ K-edge between before charge and after 1st cycle discharge. The oxidation state can be estimated as slightly lower than that of the $\mathrm{Li}_{2} \mathrm{MnO}_{3}$ which is +4. The XANES spectra of the Co absorption edge are located higher than the reference compound of $\mathrm{Co}_{3} \mathrm{O}_{4}$ and it nearly corresponds to the reference state of $\mathrm{Li}\left(\mathrm{Ni}_{1 / 3} \mathrm{Mn}_{1 / 3} \mathrm{Co}_{1 / 3}\right) \mathrm{O}_{2}$ compound $(+3)$. It is therefore concluded that $\mathrm{Co}$ is likely to exist as an oxidation state at between +2.7 and +3 .
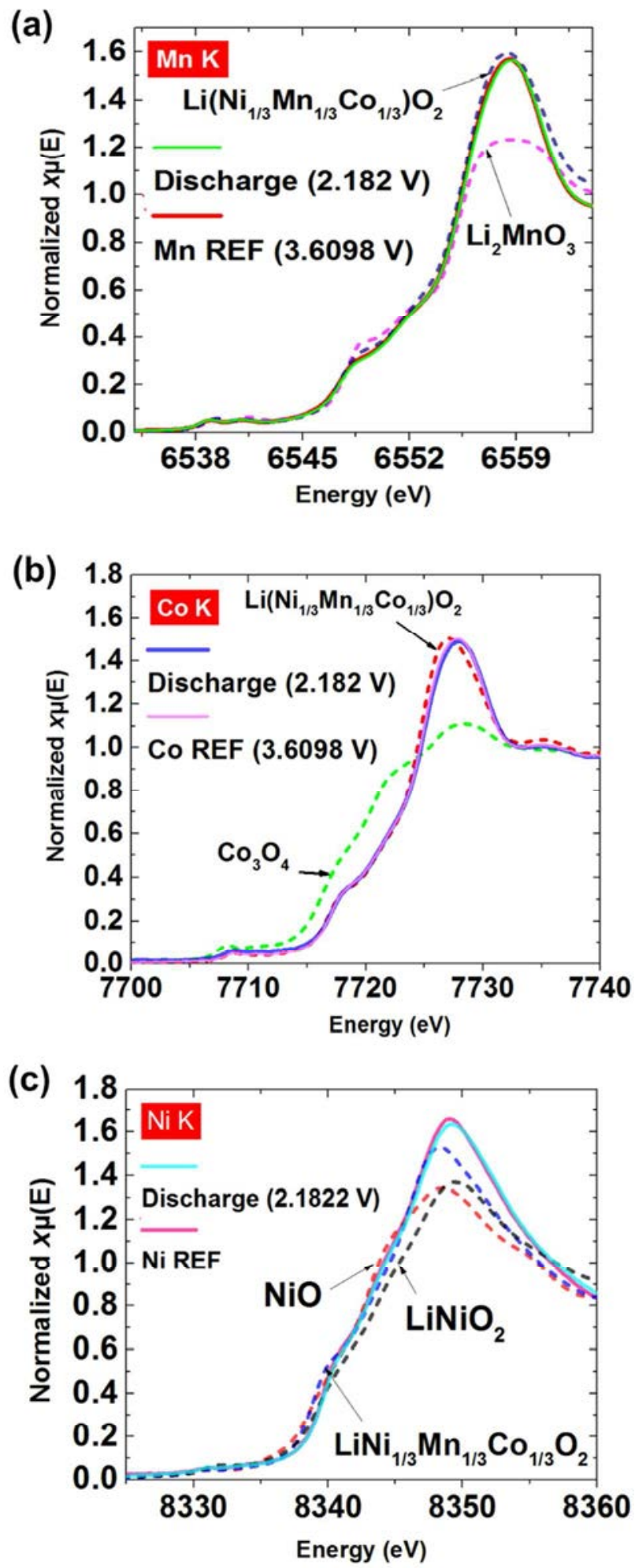

Figure 2. (a) Normalised XANES spectra at Mn K-edge in REF (no current applied) and last discharged point $(2.182 \mathrm{~V})$ of graphene-coated $\mathrm{Li}\left(\mathrm{Li}_{0.2} \mathrm{Mn}_{0.54} \mathrm{Ni}_{\text {o.13 }} \mathrm{Co}_{0.13}\right) \mathrm{O}_{2}$. (b) Normalised XANES spectra at Co K-edge in REF (no current applied) and last discharged point $(2.182 \mathrm{~V})$. (c) Normalised XANES spectra at Ni K-edge in REF (no current applied) and last discharged point $(2.182 \mathrm{~V})$. 
Similarly to Mn, the location of the Co K-edge spectra before charge and after ist cycle discharge is almost same as illustrated in Figure $2 \mathrm{~b}$. This implies minimal change of the chemical and electronic states of Mn and Co. XANES spectra at the Ni K-edge of REF in Figure $2 \mathrm{C}$ are located between those for $\mathrm{NiO}\left(\mathrm{Ni}^{2+}\right)$ and $\mathrm{LiNiO}_{2}\left(\mathrm{Ni}^{3+}\right)$, and the absorption edge is mostly identical to that of $\mathrm{Li}\left(\mathrm{Ni}_{1 / 3} \mathrm{Mn}_{1 / 3} \mathrm{Co}_{1 / 3}\right) \mathrm{O}_{2}$. This indicates that the oxidation state of $\mathrm{Ni}$ in the graphene-coated $\mathrm{Li}\left(\mathrm{Li}_{0.2} \mathrm{Mn}_{0.54} \mathrm{Ni}_{0.13} \mathrm{Co}_{0.13}\right) \mathrm{O}_{2}$ is nearly +2 .

After 1st cycle discharge, the Ni K-edge spectrum is observed to shift marginally higher than the initial state of the cathode. A slight change in the intensity at $8349 \mathrm{eV}$ could be also observed at Ni K-edge XANES after discharge. This observation can be explained by the distortion of local geometry resulting from larger oxidation change and/or Jahn-Teller effect by $\mathrm{Ni}^{3+}$. Although the $\mathrm{K}$ edge XANES spectra can provide information about local symmetry and electronic structure with oxidation state, the oxidation evaluation from the spectra location is not accurate because those spectra shifts may also arise from the crystal structure distortion or induced voltage effect during charge.
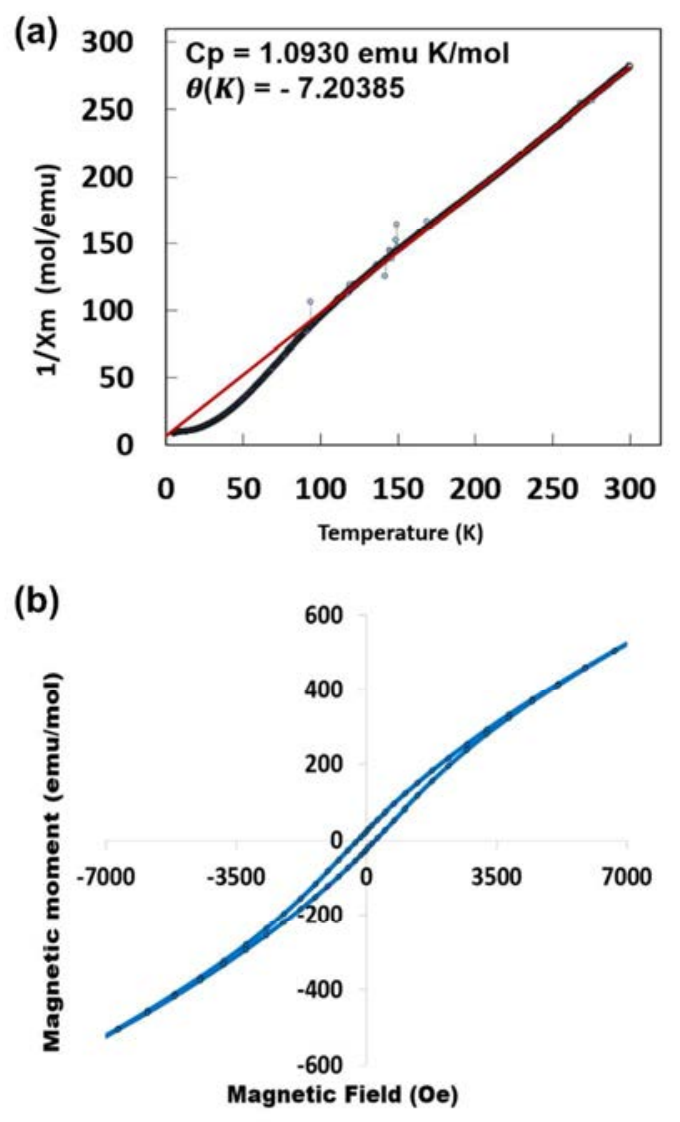

Figure 3. (a) Reciprocal magnetic susceptibility. The straight red-line is the fit to the Curie-Weiss law in the range of 150 $300 \mathrm{~K}$. Applied magnetic field is 1000 Oe. (b) Magnetization curve at $5 \mathrm{~K}$.
To determine the precise oxidation state, a magnetic measurement was performed by Superconducting Quantum Interference Device (SQUID) analysis in the temperature range of 5- $300 \mathrm{~K}$. The magnetic measurement provides the correct oxidation state of each transition element in the initial state of the $\mathrm{Li}\left(\mathrm{Li}_{0.2} \mathrm{Mn}_{0.54} \mathrm{Ni}_{0.13} \mathrm{Co}_{0.13}\right) \mathrm{O}_{2}$ cathode, as well as the vital information for the electronic structure of the transition metal oxides. Figure za exhibits the reciprocal molar magnetic susceptibility $1 / \chi_{m}(\mathrm{H} / \mathrm{M})$ of the graphene-coated composite as a function of temperature. As can be seen from the graph, the composite is paramagnetic above approximately16o $\mathrm{K}$ where it follows the Curie-Weiss law $\chi_{m}=N_{a} \mu^{2} / 3 k_{B}(T-\theta)$, with $k_{b}$ the Boltzmann constant and $N_{a}$ the Avogadro number. The Curie-Weiss temperature $(\theta)$ and the effective magnetic moment $(\mu)$ of the transition metals were determined by the fitting at the linear regime in Figure 3 a. The Curie constant $\left(C_{P}=N_{a} \mu^{2} / 3 k_{B}\right)$ and Curie-Weiss temperature were measured to be $1.0930 \mathrm{emu} \mathrm{K} / \mathrm{mol}$ and $-7.20385 \mathrm{~K}$, respectively. The negative value of the Curie-Weiss temperature implies that this system partially includes the antiferromagnetic property. The magnetic moment of the composite was calculated to be $\mu_{\text {experiment }}=2.94823 \mu_{b}$, whereas the theoretical value $\left(\mu_{\text {calculation }}\right)$ was $3.02828 \mu_{b}$. For the theoretical calculation of the magnetic moment, the oxidation state/effective magnetic moment for each transition metal were considered as $\mathrm{Mn}^{4+}$ (spin state $\left.\mathrm{S}=3 / 2, \mu_{S}=3.87 \mu_{B}\right), \quad \mathrm{Co}^{3+}\left(\mathrm{LS}, \mu_{S}=0 \mu_{B}\right)$ and $\mathrm{Ni}^{2+}$ (spin state $\left.\mathrm{S}=1, \mu_{S}=2.83 \mu_{B}\right)$. The slightly lower value of the $\mu_{\text {experiment }}$ is possibly attributed to the presence of the low spin $\mathrm{Mn}^{3+} 44,45$ in this composite. The incorporation of the low spin $\mathrm{Mn}^{3+}$ results in the theoretical value of $\mu_{\text {calculation }}=2.95767 \mu_{b}$, which is close to the experimental effective magnetic moment. With this spin states consideration, therefore, the evaluated oxidation state of the $\mathrm{Mn}, \mathrm{Co}$, and Ni were $+3.889,+3$, and +2 respectively.

Operando XANES of Mn, Co, and Ni. Figure 4 displays the spectra shifts of K-edge XANES for Mn during the ist electrochemical cycle of the graphene-coated $\mathrm{Li}$ (Lio.2Mno.54Nio.13Coo.13)O2 lithium-ion battery. The battery was cycled at $0.5 \mathrm{C}$ rate and 7 points could be taken during the initial charge-discharge. The first red point, indicated as REF, is the point at which no current was applied. The initial battery potential at this point was $\sim 3.6098$ V. Four significant absorption spectra features were identified at Mn K-edge as shown with the numbers in Figure $4 \mathrm{a}$. Absorption feature 2 is linked with the electric dipole transition from is to $4 \mathrm{p}$ with a shakedown process from ligand-to-metal charge transfer (LMCT), whereas absorption feature 4 corresponds to the dipole transition without the shakedown process. Thus, the final states of absorption feature 2 and 4 can be respectively represented as $1 s^{1} c 3 d^{n+1} L 4 p^{1}$ and $1 s^{1} c 3 d^{n} 4 p^{1}$, where $c$ is a is core hole and $\mathrm{L}$ is an oxygen $2 \mathrm{p}$ ligand $\left(\mathrm{Mn}^{4+}: \mathrm{n}=3\right)$. 
Absorption 1 indicates the Mn $\mathrm{K}$ pre-edge peaks found between 6537 and $6543 \mathrm{eV}$ as can be seen in Figure 4c. . Those two peaks are assigned to $1 \mathrm{~s}-3 \mathrm{~d}_{\mathrm{t} 2 \mathrm{~g}}$ and $1 \mathrm{~s}-3 \mathrm{~d}_{\mathrm{eg}}$ transitions which are electric dipole forbidden. The pre-edge peaks, which are formally forbidden, are attributed to a weak quadrupole transition or/and 3d-4p orbital hybridization. It appears from the loss of centrosymmetric environment by the distortion of $\mathrm{MnO}_{6}$ octahedra. A slight change of the XANES spectra shift in Mn K-edge can be observed during charge-discharge. This spectra shift may be explained by the actual oxidation change of $\mathrm{Mn}$ between +3.889 and +4 although the change is slight. In Mn $\mathrm{K}$ pre-edge, the peak intensity increases during $\mathrm{Li}^{+}$deintercalation (Figure $4 \mathrm{c}$ ).
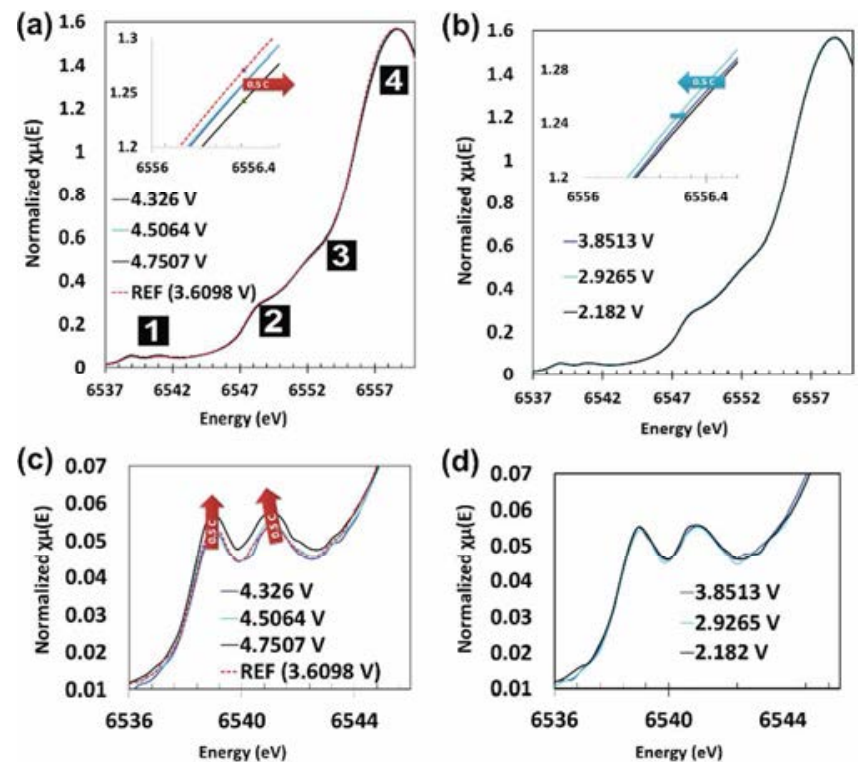

(e)

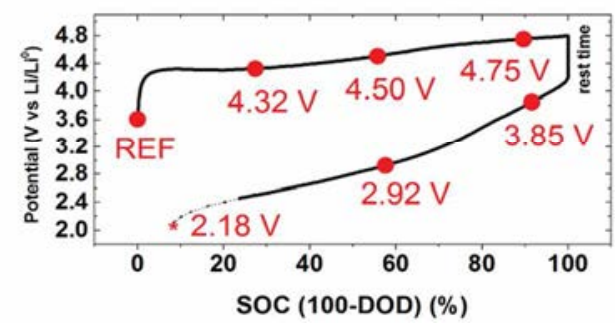

Figure 4 (a) Normalised XANES spectra shift of Mn K-edge during 1st charge and (b) 1st discharge of graphene-coated $\mathrm{Li}\left(\mathrm{Li}_{0.2} \mathrm{Mn}_{0.54} \mathrm{Ni}_{\text {o.13 }} \mathrm{Co}_{0.13}\right) \mathrm{O}_{2}$ cathode. (c) Spectra shifts at Mn K pre-edge during ist charge and (d) ist discharge. (e) Galvanostatic profile with XAS collection points (o.5 C-rate).

The normalized XANES spectra shift during the electrochemical cycle can be also observed in the Co and Ni Kedge during the ist charge, as presented in Figure 5. There is a similarity in the shape change of XANES spectra between $\mathrm{Mn}$ and $\mathrm{Co}$, which is possibly attributed to the similarity in their atomic environment. On the other hand, a single peak was shown at Co K pre-edge (Figure $2 \mathrm{~b}$ ). The appearance of this peak is attributed to the $1 s \rightarrow \mathrm{t}_{2 \mathrm{~g}}$ transi- tion of $\mathrm{Co}^{3+}\left(t_{2 g}^{6} e_{g}^{0}\right)$. The dipole forbidden transition occurred due to the hybridization between Co $d$-orbital and oxygen $p$-orbital and/or quadrupole transitions. In contrast to Mn K pre-edge, the Co pre-edge peak was not well resolved into a double-peak because of its mixed state between low-spin and high-spin and/or intermediate state of $\mathrm{Co}^{3+}$.
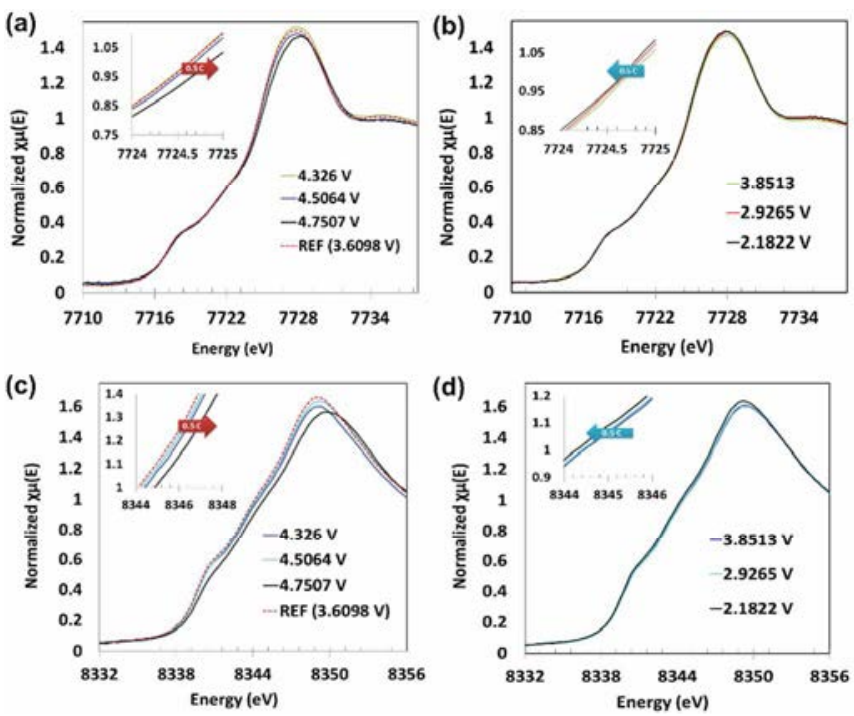

Figure 5 (a) Normalised XANES spectra shift of Co K-edge during ist charge and (b) 1st discharge of graphene-coated $\mathrm{Li}\left(\mathrm{Li}_{0.2} \mathrm{Mn}_{0.54} \mathrm{Ni}_{0.13} \mathrm{Co}_{0.13}\right) \mathrm{O}_{2}$ cathode. (c) spectra shifts of Ni Kedge during ist charge and (d) ist discharge.

The shifts in Ni K-edge reveal relatively distinct changes compared with $\mathrm{Mn}$ and $\mathrm{Co}$ as the spectral shifts of $\mathrm{Mn}$, $\mathrm{Co}$, and $\mathrm{Ni}$ K-edge were $0.4 \mathrm{eV}, 0.61 \mathrm{eV}$, and $1.07 \mathrm{eV}$, respectively. The oxidation changes of the transition metals are likely to contribute to the charge compensation mechanism of the $\mathrm{Li}\left(\mathrm{Li}_{0.2} \mathrm{Mn}_{0.54} \mathrm{Ni}_{0.13} \mathrm{Co}_{0.13}\right) \mathrm{O}_{2}$ cathode. The large XANES spectra shift of the $\mathrm{Ni}$ can be explained by the two-stage redox reaction between $\mathrm{Ni}^{2+} / \mathrm{Ni}^{3+}$ and $\mathrm{Ni}^{3+} / \mathrm{Ni}^{4+}{ }^{16,29,46}$. The compensation mechanism that describes the involvement of each transition metal during charge-discharge is not yet clearly understood. Previous studies $^{32,47,48}$ reported that the direct contribution of the $\mathrm{Ni}^{2+}$ and $\mathrm{CO}^{3+}$ to the battery specific capacity during charge. The XANES spectra of Ni and Co K-edge gradually increase until $57 \%$ SOC, but a marked shift in the photon energy $(\mathrm{eV})$ has been observed at $\sim 89 \%$ SOC. The pattern of change in the spectra during discharge (Figure $5 \mathrm{~d}$ ) was similar to that during charging, reversed. The energy change was relatively smaller compared to the XANES shift on charge for each transition metal. The pre-edge peaks at Ni K-edge appeared to be very weak as displayed in Figure 2c. The octahedral structure of $\mathrm{Ni}^{2+}$ allows the transition from is to $\mathrm{e}_{\mathrm{g}}$ with the loss of centrosymmetric environment, and it can thus be assumed that there is a slight distortion in octahedral $\mathrm{NiO}_{6}$. 
Operando EXAFS of $\mathrm{Mn}, \mathrm{Co}$, and $\mathrm{Ni}$ with Wavelet Transform Analyses. Figure 6 reveals the operando EXAFS measurements of Mn K-edge during the ist cycle in the graphene-coated $\mathrm{Li}\left(\mathrm{Li}_{0.2} \mathrm{Mn}_{0.54} \mathrm{Ni}_{0.13} \mathrm{Co}_{0.13}\right) \mathrm{O}_{2}$ cathode. High quality EXAFS data were obtained for Mn Kedge in the $k$-space range of $0-12 \AA^{-1}$ during chargedischarge. The results are presented in Figure 6a. The Fourier transformed EXAFS data at different states of charge, as displayed in Figure $6 \mathrm{~b}$, shows that the amplitude of Mn-O is always higher than the Mn-TM amplitude ( $\mathrm{TM}=\mathrm{Mn}, \mathrm{Co}$, and $\mathrm{Ni}$ ) throughout the cycle. This might be explained in part of the cation ordering in the $\mathrm{xLi}_{2} \mathrm{MnO}_{3} \cdot(1-\mathrm{x}) \mathrm{LiMO}_{2}(\mathrm{M}=\mathrm{Mn}, \mathrm{Ni}, \mathrm{Co})$ composite system ${ }^{49-51}$. The atomic environment around $\mathrm{Mn}$ is wellcoordinated with six neighboring atoms of oxygen $\left(\mathrm{MnO}_{6}\right)$ in the layered component. On the other hand, relatively smaller numbers of transition metals surround the $\mathrm{Mn}$ absorber as the transition metals could be partially substituted with light scatterers such as oxygen vacancies or lithium ions. As a consequence, the peak intensity is always higher in the ist shell because of the nearestneighboring oxygen ions during the (de)intercalation process. The intensity of the peaks (Mn-O/Mn-TM) decreases during the discharge, but a larger drop was observed for Mn-TM in the voltage range from $3.8513 \mathrm{~V}$ to $2.1822 \mathrm{~V}$. It seems possible that the migration environment of the transition metals during discharge is slightly different to that of the charge in the layered oxide structure. The difference of Mn-O between largest ( 1.50 $\AA)$ and smallest $(\sim 1.44 \AA)$ value in R-space (uncorrected for phase shift) was approximately o.06 $\AA$ during chargedischarge, indicating a slight change of the local atomic environment. The intensity of the higher coordination shells of Mn approximately at 4.31/5.24 Å tends to drop upon discharge and the peak intensities are lower compared with the peaks during charge (Figure $6 \mathrm{~b}$ ). The decrease of the 1st shell peak is likely to be attributed to the oxygen loss and/or structural disorder in the octahedral $\mathrm{MnO}_{6}$ environment on charge-discharge. The dramatic drop of Mn-TM peak implies the cation ordering of $\mathrm{LiMn}_{6}$ in the transition metal layers ${ }^{50}$.

The variation patterns of the EXAFS $\chi(k)$ at Mn K-edge during charge were similar in $k$-space and R-space at different state of charge (SOC). In the same way, the variation patterns during discharge were similar at different depth of discharge (DOD). It can thus be suggested that the atomic environment of $\mathrm{Mn}$ in the graphene-coated $\mathrm{Li}\left(\mathrm{Li}_{0.2} \mathrm{Mn}_{0.54} \mathrm{Ni}_{0.13} \mathrm{Co}_{0.13}\right) \mathrm{O}_{2}$ cathode is likely to maintain good stability during the electrochemical cycle. (a)

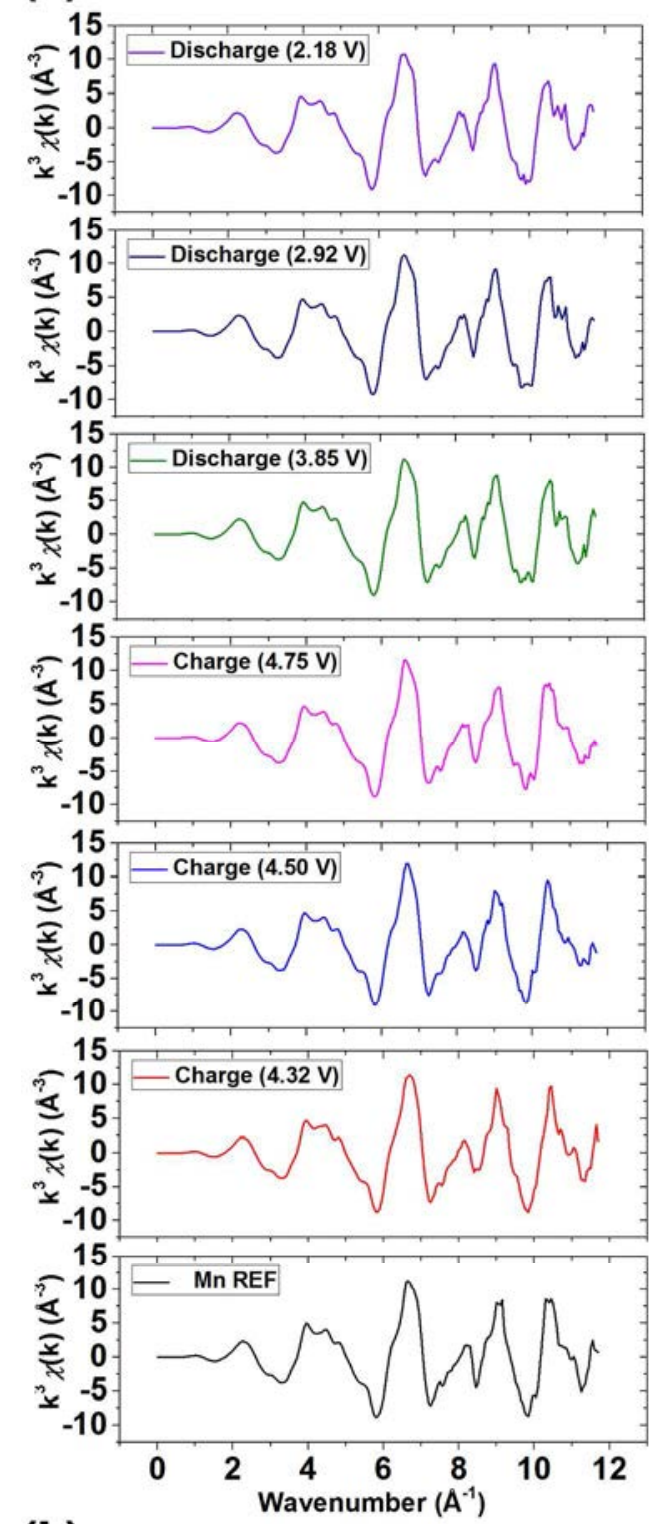

(b)

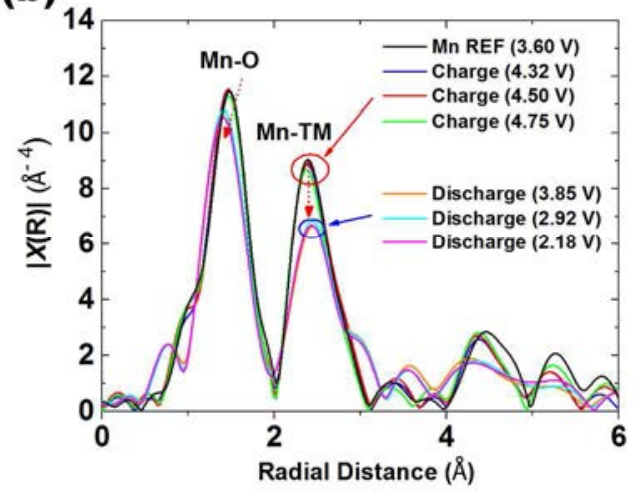

Figure 6 (a) Operando EXAFS measurement of Mn in graphene-coated $\mathrm{Li}\left(\mathrm{Li}_{0.2} \mathrm{Mn}_{0.54} \mathrm{Ni}_{0.13} \mathrm{Co}_{0.13}\right) \mathrm{O}_{2 .}$ during the ist cycle with $\mathrm{k}^{3}$-weighted EXAFS oscillations $\chi(k)$ above Mn K-edge during charge-discharge. (b) $\mathrm{k}^{3}$-weighted Fourier transform magnitudes of Mn K-edge during charge-discharge $(\mathrm{TM}=$ $\mathrm{Mn}, \mathrm{Co}$, and $\mathrm{Ni}$ ). Red and blue arrows indicate charge and discharge, respectively. 

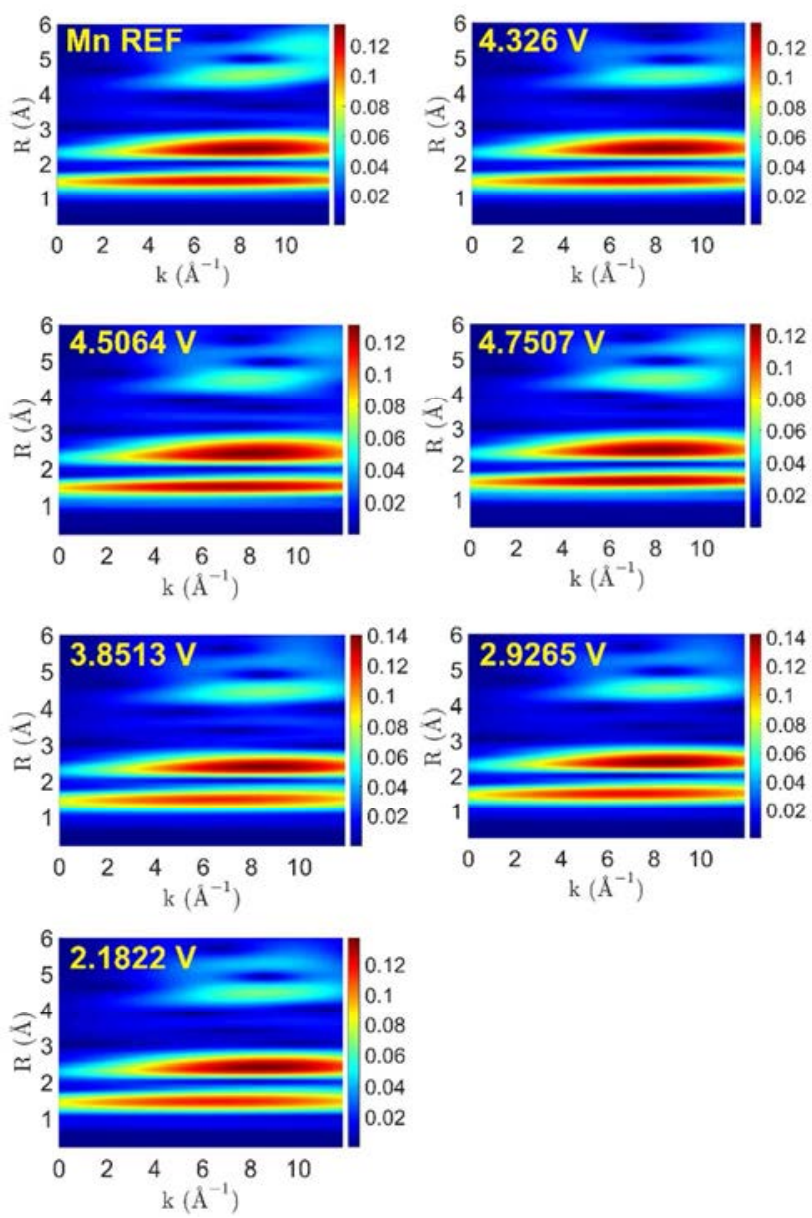

Figure 7 Continuous Cauchy wavelet transform (CCWT) analyses on the Mn K-edge EXAFS signal of graphene-coated $\mathrm{Li}\left(\mathrm{Li}_{0.2} \mathrm{Mn}_{0.54} \mathrm{Ni}_{0.13} \mathrm{Co}_{0.13}\right) \mathrm{O}_{2}$ cathode during the ist cycle at different voltage levels. The color intensity is the magnitude of the CCWT modulus. Dark-red signifies higher intensity, while blue is the lower intensity.

To further understand the EXAFS signals for the complex composite, a Continuous Cauchy Wavelet Transform (CCWT) analysis ${ }^{33}$ was performed for each transition metal. The CCWT enables the visualization of the EXAFS spectra in three dimensions by decomposing the $k$-space and $R$-space (uncorrected for phase shift) signals ${ }^{33,52,53}$. As a result, the wavelet transform provides detailed information on the local atomic structure with the visualized signals which are difficult to be identified in a onedimensional decomposition such as Fourier Transform EXAFS $^{53}$. Figure 7 compares the CCWT analyses of the Mn K-edge EXAFS upon charge and discharge. The color intensity is proportional to the CCWT modulus that corresponds to the decomposition of the EXAFS amplitude term $^{33}$. The locations of the highest intensity for $\mathrm{Mn}-\mathrm{O}$ and Mn-TM in k-space were $\sim 7.1 \AA^{-1}$ and $\sim 8.5 \AA^{-1}$, respectively, at the reference point (labelled as REF). (a)
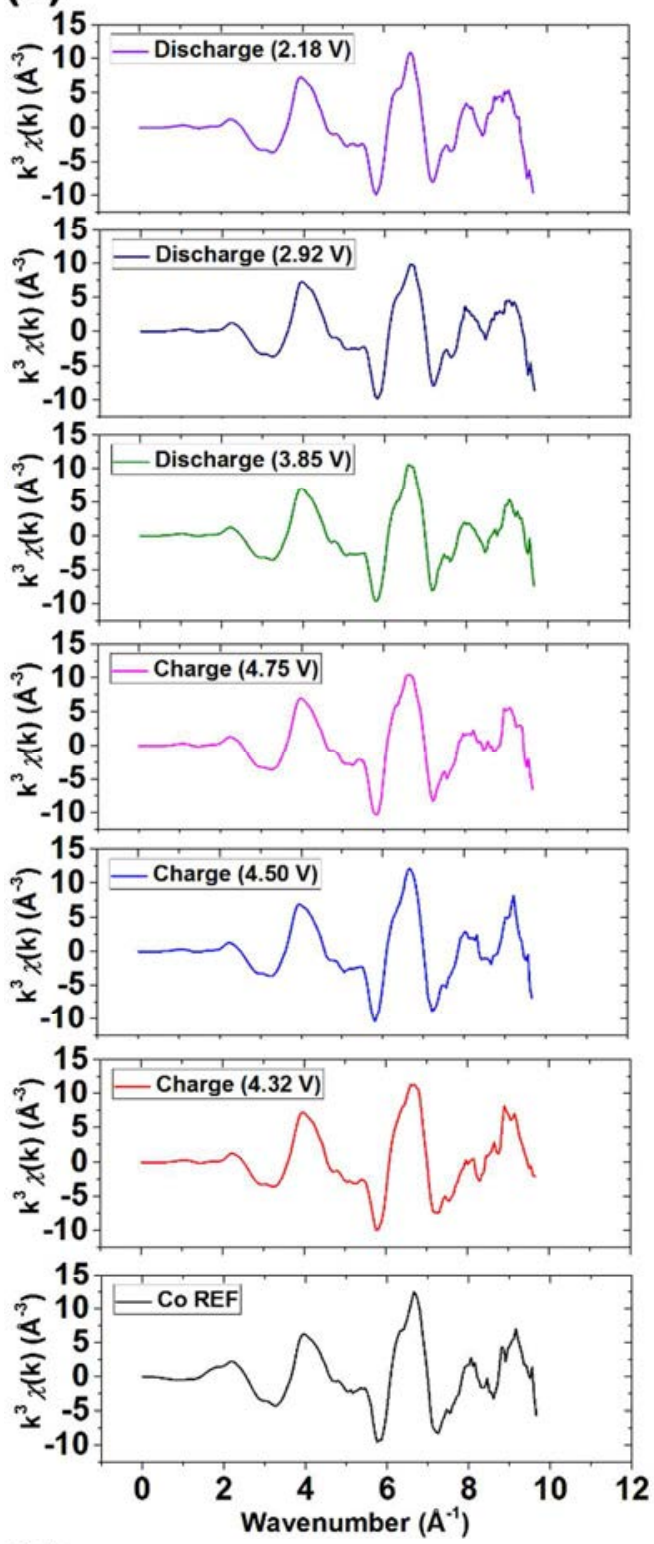

(b)

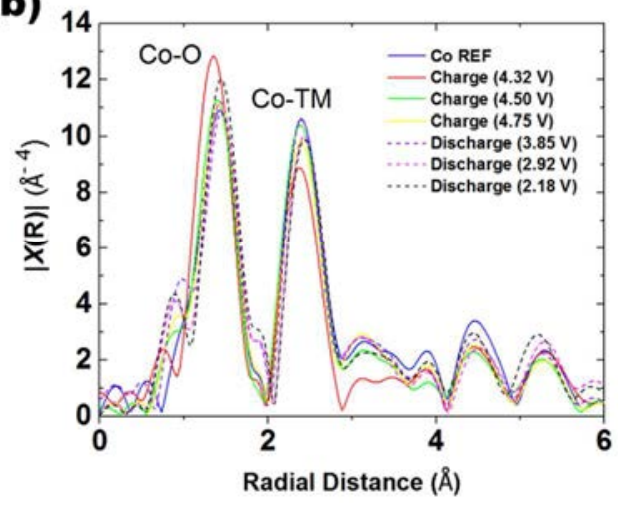

Figure 8 (a) Operando EXAFS measurement of $\mathrm{Co}$ in graphene-coated $\mathrm{Li}\left(\mathrm{Li}_{0.2} \mathrm{Mn}_{0.54} \mathrm{Ni}_{0.13} \mathrm{Co}_{0.13}\right) \mathrm{O}_{2}$.during the ist cycle with $\mathrm{k}^{3}$-weighted EXAFS oscillations $\chi(k)$ above Co K-edge during charge-discharge. (b) $\mathrm{k}^{3}$-weighted Fourier transform magnitudes of Co K-edge during charge-discharge (TM = $\mathrm{Mn}, \mathrm{Co}$, and $\mathrm{Ni})$. Red and blue arrows indicate charge and discharge, respectively. 
An element with higher atomic number appears more intense at high $k$-space due to more efficient backscattering. High order shells were also observed at $\mathrm{k} \sim 8.7 \AA^{-1}$ and $\mathrm{k} \sim 11.0 \AA^{-1}$, but they are most likely related to the multiple scattering effects from the combined transition metals ( $\mathrm{Mn}, \mathrm{Co}$, and $\mathrm{Ni}$ ) as the CCWT modulus exhibits blurry appearance. One interesting observation from this visual inspection is that the highest coordination shell at $\mathrm{k} \sim 11$.o $\AA^{-1}(\mathrm{R} \sim 5.42 \AA)$ is losing its signal intensity, while the second highest coordination shell $\left(\mathrm{k} \sim 8.7 \AA^{-1}\right.$ and $\mathrm{R} \sim 4.46 \AA$ ) retains the intensity during charge and discharge. This finding may suggest the migration of transition metals into the Li-layer. The shape of wavelet transform on MnTM is nearly symmetric and displays high intensity (darkred), indicating highly ordered atomic environment of Mn-TM. In addition, as mentioned above, the second highest coordination shell $\left(\sim 8.7 \AA^{-1}\right)$ reveals consistent multiple scattering signals from the transition metals during $\mathrm{Li}^{+}$(de)intercalation. Another interesting point is the Mn-O signal. During charge, it was possible to observe the highest intensity (dark-red) of the CCWT modulus at 4.5064 V and 4.7507 V as can be seen in Figure 7. However, this was not the case during battery discharge. It is therefore likely that there has been a slight modification in the structure around the Mn absorber after full charge. This observation is likely to be attributed to the lithia $\left(\mathrm{Li}_{2} \mathrm{O}\right)$ extraction, which results in the activation of the $\mathrm{Li}_{2} \mathrm{MnO}_{3}$ component for the battery charge compensation mechanism at the higher voltage.

Figure 8 presents the results obtained from the operando EXAFS measurement of Co K-edge in $k$-space and Rspace during charge-discharge. The difference of Co-O between largest $(\sim 1.41 \AA)$ and smallest $(\sim 1.50 \AA)$ value in $R$-space (uncorrected for phase shift) was evaluated to be $\sim 0.09 \AA$ during the 1st cycle, and this difference was $33 \%$ higher than that of the Mn-O. This implies larger local atomic environment change in the Co-O. With the CCWT analyses, in Figure 9, it can be also identified that the atomic environment of Co-O/Co-TM $\left(\sim 6.5 \AA^{-1} / \sim 8.4 \AA^{-1}\right.$ in k-space) show a structural disorder from the initial point (labelled as REF) as the CCWT shapes were less symmetric compared with $\mathrm{Mn}-\mathrm{O} / \mathrm{Mn}-\mathrm{TM}$. This may be explained by some defects in the synthesis condition of the $\mathrm{Li}\left(\mathrm{Li}_{\mathrm{O} .2} \mathrm{Mn}_{\text {0.54 }} \mathrm{Ni}_{\text {o.13 }} \mathrm{Co}_{\text {o.13 }}\right) \mathrm{O}_{2}$ composite. Although the atomic environment between Co and TM is disordered from the initial state, it is likely to keep its local symmetry since the highest CCWT intensity (dark-red at $\sim 8.4 \AA^{-1}$ in $k$-space, $\mathrm{R} \sim 2.46 \AA$ ) exhibits little changes during chargedischarge. This can be also observed in the R-space of the Co K-edge as shown in Figure 8 as the EXAFS pattern shows relatively less alteration in the 2 nd order shell (CoTM) during charge-discharge. On the other hand, the highest intensity of the CCWT modulus in the Co-O shell changes during the ist cycle. This would be attributed to the compensation mechanism from the Co with the oxygen removal during the $\mathrm{Li}^{+}$(de)intercalation leading to the modification of the Co-O local environment.
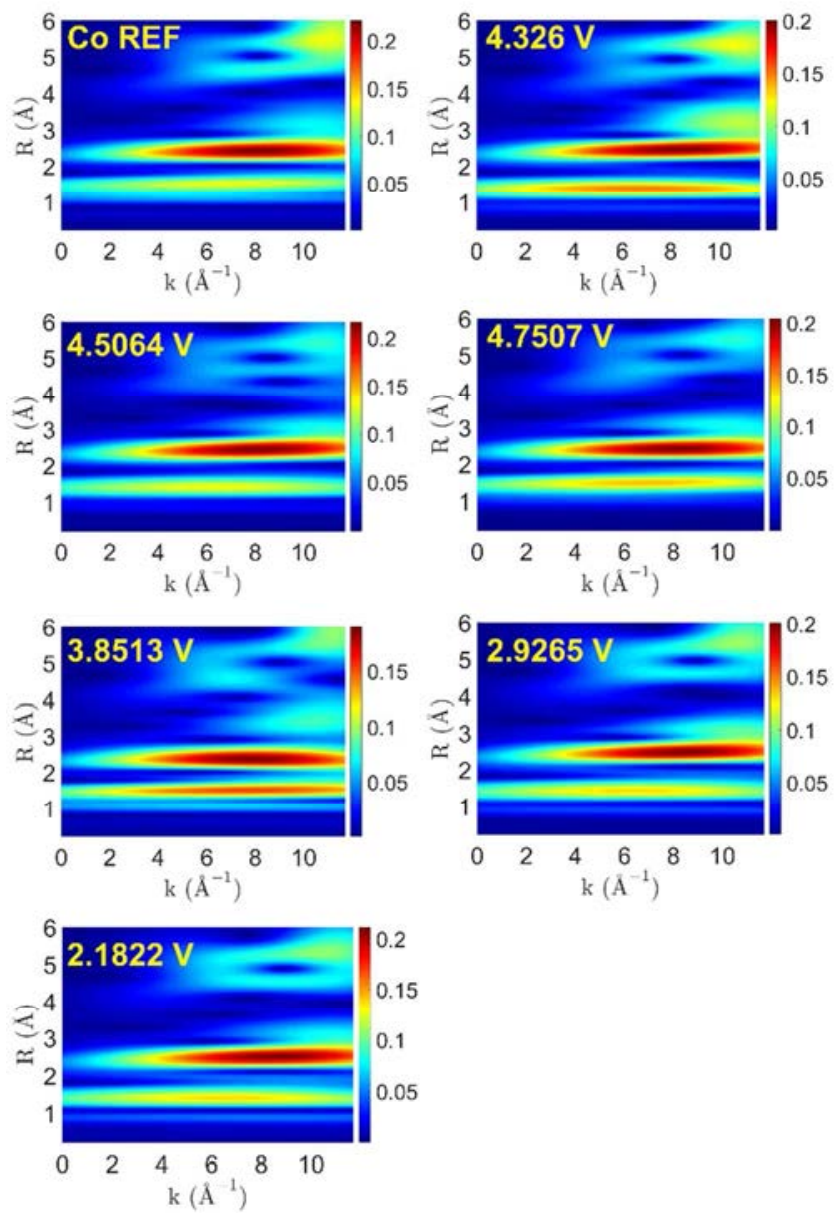

Figure 9 Continuous Cauchy wavelet transform (CCWT) analyses on the Co K-edge EXAFS signal of graphene-coated $\mathrm{Li}\left(\mathrm{Li}_{\mathrm{O} .2} \mathrm{Mn}_{0.54} \mathrm{Ni}_{0.13} \mathrm{Co}_{0.13}\right) \mathrm{O}_{2}$ cathode during the ist cycle at different voltage levels. The color intensity is the magnitude of the CCWT modulus. Dark-red signifies higher intensity, while blue is the lower intensity.

The visual information from Figure 7 and Figure 9 suggests that the redox reaction of Co contributes to the battery capacity over the entire voltage range, while $\mathrm{Mn}$ is only involved at $>\sim 4.5 \mathrm{~V}$ during charging. The 3 rd order shell from the Co K-edge is located at around $5.3 \AA$ (uncorrected for phase shift). There was a similarity in the local atomic environment of the highest order shell between the REF $(3.6098 \mathrm{~V}$ ) and $4.326 \mathrm{~V}$. At these two points, the formation of the EXAFS signal is mostly attributed to single scattering paths although the visualization of the signals looks rather blurred compared with the 1st or 2nd shells. However, the tendency of having single scattering disappears from $4.5064 \mathrm{~V}$ and the contributions from multiple scattering increase, as can be seen from the CCWT signals on further charge and the discharge. The trend of the Co K-edge CCWT is comparable to that ana- 
lyzed in Mn K-edge during the 1st cycle. Obviously, the local atomic environments are different between the Co $\mathrm{K}$-edge and Mn K-edge, but there is a clear similarity in terms of the trend in the phase change relevant to the voltage. At first, both elements show a notable change in the center of the highest intensity from one of their shells (1st shell for Mn K-edge and 3rd shell for Co K-edge) at before and behind $\sim 4.5 \mathrm{~V}$. At second, with those shells, the phase change with the local atomic environment seems to be irreversible as the trend of the intensity change on charge differs from discharge.

Figure 10 compares the results obtained from the operando EXAFS measurement of Ni K-edge in $k$-space and Rspace during the initial cycle. The Fourier transformed EXAFS data at Ni K-edge (Figure 1ob) reveals complicated local environment changes in R-space. On chargedischarge, both the amplitude and the location of the $\mathrm{Ni}$ $\mathrm{O} / \mathrm{Ni}$-TM peaks change significantly. The maximum deviation from the REF point of $\mathrm{Ni}-\mathrm{O}$ was $0.13 \AA$ (uncorrected for phase shift) in R-space, which is more than two times higher that of the Mn-O (= o.o6 $\AA$ ). The larger difference of the R-space shift in Ni can be explained by the two stage oxidation changes from $\mathrm{Ni}^{2+} / \mathrm{Ni}^{3+}$ to $\mathrm{Ni}^{3+} / \mathrm{Ni}^{4+}$ which result in higher local structure modification. It should be also considered that the Jahn-Teller effect from $\mathrm{Ni}^{3+}\left(\mathrm{d}^{7}\right)$ with an electronic configuration of $t_{2 g}^{6} e_{g}^{1}$ contributes to the significant local environment changes.

The CCWT analysis from Figure 11 also reveals a complicated environment change of $\mathrm{Ni}-\mathrm{O} / \mathrm{Ni}-\mathrm{TM}$ during the ist cycle. At REF state, the highest order shell at $9.8 \AA^{-1}$ in k-space $(\mathrm{R} \sim 5.7 \AA)$ was clearly observed mostly with single scattering effect. Once the current (o.5 C) was applied, the effect from multiple scattering increases leading to the blurry appearance of that shell signature. This observation could be attributed to the multiple scattering impacts from diverse transition metals migration upon charge. From the ist shell Ni-O CCWT, we can see that the peak intensity corresponding to $\sim 5.8 \AA^{-1}$ in k-space (R $1.5 \AA$ A) drops during charge-discharge and reveals splits in the shape from $2.9265 \mathrm{~V}$ to $2.1822 \mathrm{~V}$. This implies significant distortion in the octahedral coordination of the $\mathrm{Ni}$ absorber in the 1st shell. The trend is similar in the 2nd shell (Ni-TM), but the symmetry change in the and shell exhibits relatively lower degree as the center $\left(\sim 6.78 \AA^{-1}\right.$ in $\mathrm{k}$-space) of the shell retains the highest intensity (darkred) during charge-discharge. Interestingly, the Ni K-edge CCWT indicates that the atomic environment change during $\mathrm{Li}^{+}$(de)intercalation is irreversible since there is a distinctive difference in the shape and scattering effects between charge and discharge, whereas $\mathrm{Mn}$ and Co shows similar visualization patterns. (a)

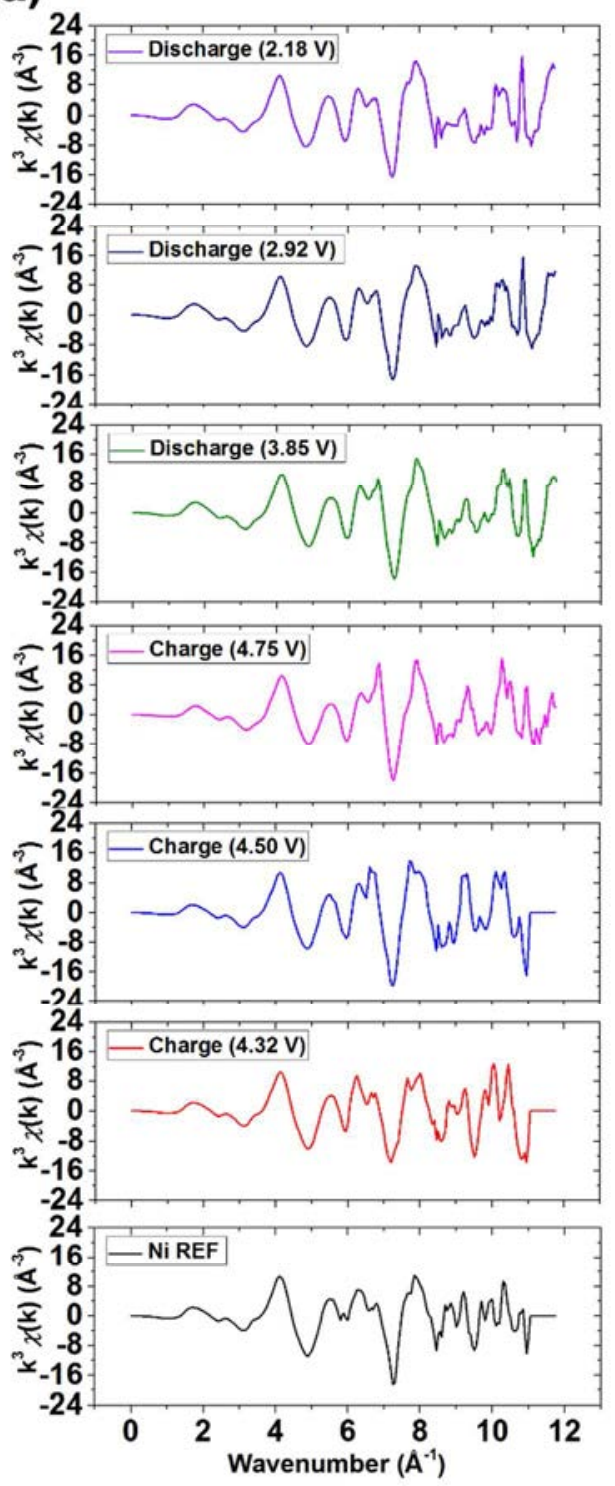

(b)

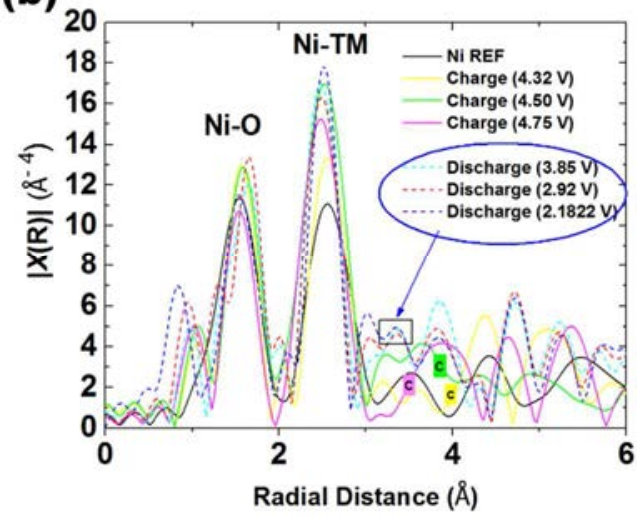

Figure 10 (a) Operando EXAFS measurement of $\mathrm{Ni}$ in graphene-coated $\mathrm{Li}\left(\mathrm{Li}_{0.2} \mathrm{Mn}_{0.54} \mathrm{Ni}_{\text {o.13 }} \mathrm{Co}_{0.13}\right) \mathrm{O}_{2 .}$ during the ist cycle with $\mathrm{k}^{3}$-weighted EXAFS oscillations $\chi(k)$ above Ni K-edge during charge-discharge. (b) $\mathrm{k}^{3}$-weighted Fourier transform magnitudes of Ni K-edge during charge-discharge ( $\mathrm{TM}=\mathrm{Mn}$, $\mathrm{Co}$, and $\mathrm{Ni}$ ). Red and blue arrows indicate charge and discharge, respectively. 

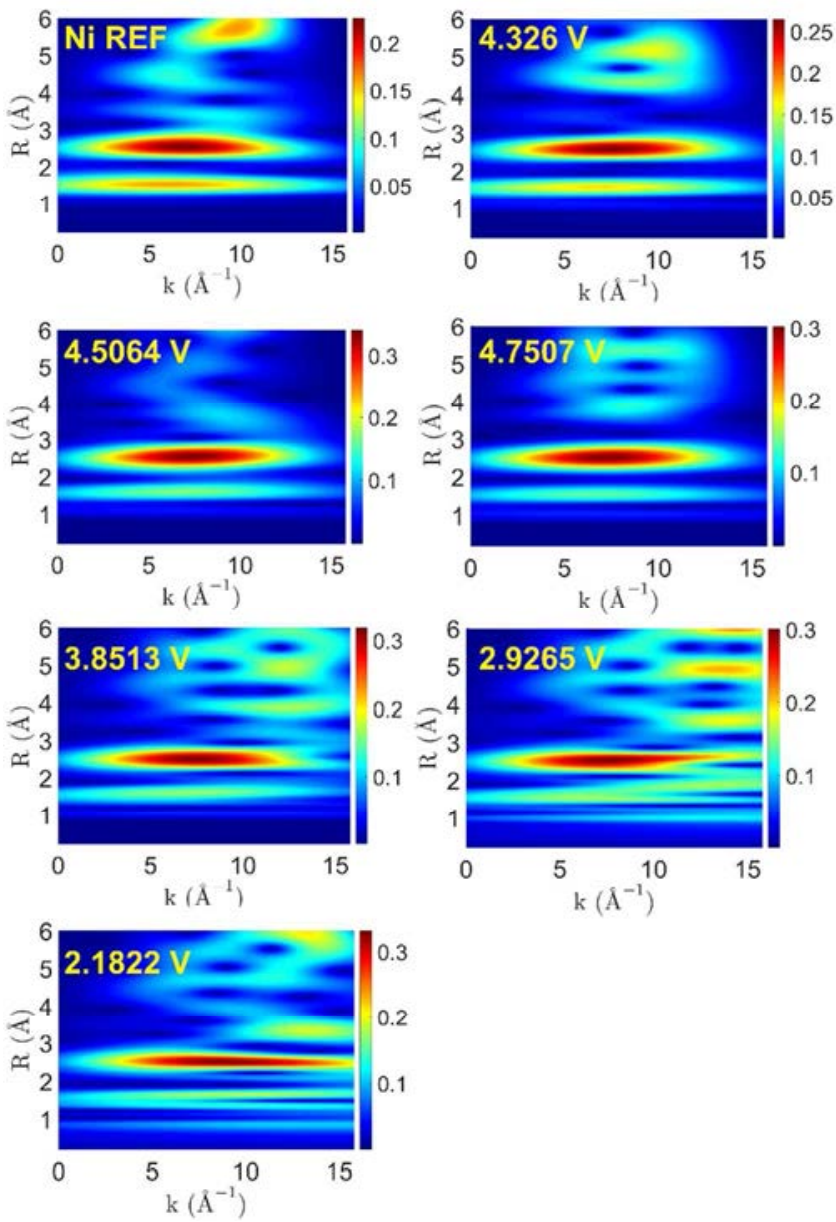

Figure 11 Continuous Cauchy wavelet transform (CCWT) analyses on the Ni K-edge EXAFS signal of graphene-coated $\mathrm{Li}\left(\mathrm{Li}_{\mathrm{O} .2} \mathrm{Mn}_{0.54} \mathrm{Ni}_{\text {O.13 }} \mathrm{Co}_{0.13}\right) \mathrm{O}_{2}$ cathode during the ist cycle at different voltage levels. The color intensity is the magnitude of the CCWT modulus. Dark-red signifies higher intensity, while blue is the lower intensity.

From the evaluation of oxidation states with Ni XANES (Figure 2c), it is obvious that the oxidation state change is reversible in $\mathrm{Ni}-\mathrm{O}$. However, although the redox reaction of $\mathrm{Ni}$ seems to be reversible, the $\mathrm{Ni}$ octahedral symmetry undergoes an irreversible atomic environment change as identified by the Ni K-edge CCWT analyses. This structural change appears to be the consequence of bondlength separation (long, short) of $\mathrm{Ni}-\mathrm{O}$ attributed to the Jahn-Teller effect from $\mathrm{Ni}^{3+}$.

Figure 12 represents the evolution of the TM-O bond length changes with the mean-square disorder $\left(\sigma^{2}\right)$ from the EXAFS Debye-Waller factor at different voltage levels during the ist electrochemical cycle. Major EXAFS parameters such as distance to neighboring atom $(R)$, EXAFS Debye-Waller factor $\left(e^{-2 \sigma k^{2}}\right)$, energy shift $\left(\Delta E_{0}\right)$, and amplitude reduction factor $\left(S_{0}^{2}\right)$ were determined by the EXAFS fitting. The EXAFS Debye-Waller factor can represent either thermal disorder or structural disorder of the central absorbing elements ( $\mathrm{Mn}, \mathrm{Co}$, and $\mathrm{Ni})^{54,55}$. $\mathrm{s}$ this experiment was performed at a constant room temperature, the result of the mean-square disorder $\left(\sigma^{2}\right)$ is likely to represent the structural disorder of the cathode material during the $\mathrm{Li}^{+}$(de)intercalation. In previous, the amplitude reduction factors $\left(S_{0}^{2}\right)$ were determined to be 0.7 , 0.67 , and 0.92 for $\mathrm{Mn}, \mathrm{Co}$, and $\mathrm{Ni}$, respectively, according to reference samples.
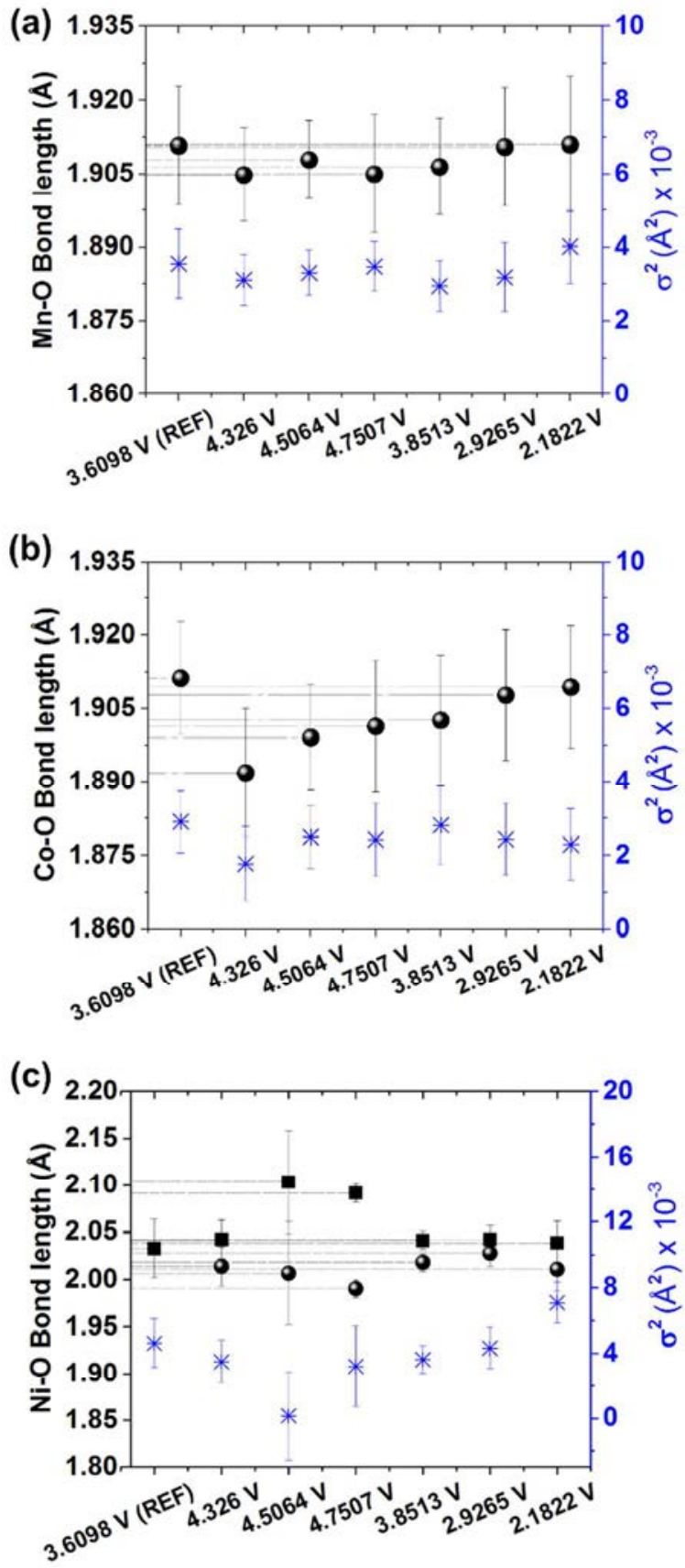

Figure 12 (a) Evolution of the 1st shell Mn-O bond length and structural disorder $(\sigma)$ changes, (b) ist shell Co-O bond length and structural disorder $(\sigma)$ changes, and (c) ist shell $\mathrm{Ni}-\mathrm{O}$ bond length and structural disorder $(\sigma)$ changes during charge-discharge for the graphene coated cathode.

The interatomic bond of $\mathrm{Mn}-\mathrm{O}$ slightly decreases upon charge, and the difference was $\sim 0.006 \AA$. The largest dif- 
ference in the Co-O appears to be $0.02 \AA$, which is higher than that of the Mn-O. This can be explained by the redox reaction between $\mathrm{Co}^{3+}$ and $\mathrm{Co}^{4+}$. The trend of the structural disorder $\left(\sigma^{2}\right)$ of $\mathrm{Mn}-\mathrm{O}$ is comparable to that evaluated in the $\mathrm{Co}-\mathrm{O}$ changes during the 1st cycle. There is a similarity in the trend of structural disorder $\left(\sigma^{2}\right)$ between them except at the last discharge point $(2.1822 \mathrm{~V})$.

The trend of the structural disorder $\left(\boldsymbol{\sigma}^{2}\right)$ in the and shells displayed relatively higher fluctuations compared with the 1st shells both in the $\mathrm{Mn}$ and $\mathrm{Co}$ as exhibited in Figure 13. Interestingly, the maximum value (o.01 $\left.\AA^{2}\right)$ of the $\sigma^{2}$ in Mn-TM changes could be observed at $4.5064 \mathrm{~V}$ while the minimum value (o.0004 $\AA^{2}$ ) of the the $\sigma^{2}$ in CoTM changes was found at the same voltage point. On the other hand, the largest difference in the $\mathrm{Ni}-\mathrm{O}$ changes was measured to be $0.11 \AA$ which is the highest bond length changes among the ist shell TM-O. As a consequence of two-stage oxidation changes between $\mathrm{Ni}^{2+} / \mathrm{Ni}^{3+}$ and $\mathrm{Ni}^{3+} / \mathrm{Ni}^{4^{+}}$, it appears that the trend of the ionic radius changes well matches to the average oxidation states. This result is consistent with the $\mathrm{Ni}$ K-edge XANES that showed the largest spectra shift during the initial chargedischarge as can be seen in Figure 2. From the EXAFS fitting, it was possible to observe the $\mathrm{Ni}-\mathrm{O}$ bond splitting (long $\mathrm{Ni}-\mathrm{O}$ and short $\mathrm{Ni}-\mathrm{O}$ ) resulting from Jahn-Teller distortion of $\mathrm{Ni}^{3^{+}}\left(\mathrm{d}^{7}\right)$ as shown in Figure 12c. The largest difference between long $\mathrm{Ni}-\mathrm{O}$ and short $\mathrm{Ni}-\mathrm{O}$ could be identified at $4.5064 \mathrm{~V}$, and the splitting tends to reduce during further charge-discharge. The bond length at the last discharge point $(2.1822 \mathrm{~V})$ of $\mathrm{Ni}^{2+}-\mathrm{O}$ was $2.038 \AA$ which is almost identical to that of the REF point as it was $2.032 \AA$. It is apparent that the oxidation change is reversible during $\mathrm{Li}^{+}$(de)intercalation. However, it seems that the local atomic environment irreversibly changed between charge and discharge because of the impact from the Ni Jahn-Teller distortion. Although the tendency of the Ni-O splitting decreased, the essential effect was still there during the discharge (Figure 12c). The irreversible change of the atomic environment between charge $($ REF $\sim 4.7507 \mathrm{~V})$ and discharge $(3.8513 \mathrm{~V} \sim 2.1822 \mathrm{~V})$ could be also clearly examined with the CCWT analysis on Ni Kedge as illustrated in Figure 11. The largest structural disorder of $\mathrm{Ni}\left(0.014 \AA^{2}\right)$ was found at $4.5064 \mathrm{~V}$ in Ni-TM bond length. The combined observations from the structural disorder $\left(\sigma^{2}\right)$ between $\mathrm{Mn}, \mathrm{Co}$, and $\mathrm{Ni}$ imply distinctive activations in Mn-TM and Ni-TM at $4.5064 \mathrm{~V}$. This may be explained by the electrochemical activation of $\mathrm{Mn}$ from the $\mathrm{Li}_{2} \mathrm{MnO}_{3}$ component in the graphene-coated $\mathrm{Li}\left(\mathrm{Li}_{0.2} \mathrm{Mn}_{0.54} \mathrm{Ni}_{0.13} \mathrm{Co}_{0.13}\right) \mathrm{O}_{2}$ cathode. It may be also the case due to the process involved the migration of transition metals during charge at $\sim 4.5064 \mathrm{~V}$. The structural disorder $\left(\sigma^{2}\right)$ in the 2nd shells displayed relatively larger value compared with the ist shells both in the Mn and Co as exhibited Figure 13.
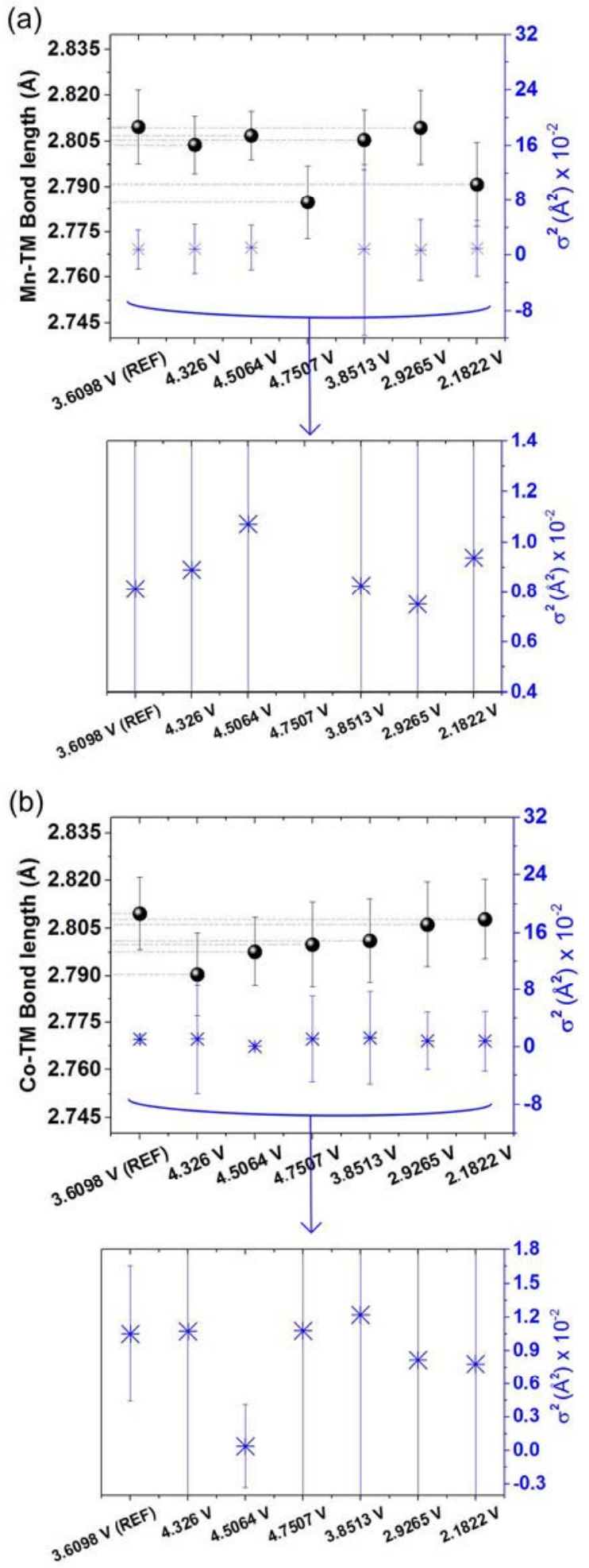

Figure 13 (a) Evolution of the 2nd shell Mn-O bond length and structural disorder $(\sigma)$ changes and (b) and shell Co-O bond length and structural disorder $(\sigma)$ changes during charge-discharge for the graphene coated cathode.

\section{CONCLUSION}

This study has presented, for the first time, an operando XAS examination with a wavelet transform ${ }^{56}$ analysis on the atomic environment of the transition metals ( $\mathrm{Mn}, \mathrm{Co}$, 
and $\mathrm{Ni}$ ) in the graphene-coated $\mathrm{Li}\left(\mathrm{Li}_{\mathrm{O} .2} \mathrm{Mn}_{\mathrm{0.54}} \mathrm{Ni}_{\text {o.13 }} \mathrm{Co}_{\text {o.13 }}\right) \mathrm{O}_{2}$ cathode. The precise correlation of the atomic environment with oxidation/electronics states of the transition metals during the ist electrochemical cycle is a key factor for designing a high energy density Li-rich oxide cathode, generally denoted as $\mathrm{xLi}_{2} \mathrm{MnO}_{3} \cdot(1-\mathrm{x}) \mathrm{LiMO}_{2}{ }^{1}$, with improved stability. We were able to characterize the correct atomic environments of each transition metal during the 1st cycle (0.5 $\mathrm{C}$ rate) with the visualization of the CCWT modulus ${ }^{56}$, which corresponds to the continuous decomposition of EXAFS amplitudes, by decomposing the kspace and R-space signals from the K-edge EXAFS of Mn, $\mathrm{Co}$, and $\mathrm{Ni}$. The combined estimations between XANES and SQUID measurement suggest that the oxidation change during $\mathrm{Li}^{+}$(de)intercalation is likely to be reversible $(\mathrm{Mn}:+3.889$, $\mathrm{Co}:+3$, and $\mathrm{Ni}:+2)$. This can be supported by the EXAFS evaluations for the inter-atomic bond length changes as the bond lengths of Mn-O, Co-O, and $\mathrm{Ni}-\mathrm{O}$ tend to recover their initial values. The observation with the operando CCWT analyses provide a diverse insight into the atomic environment change, for instance, the local atomic distortion from the Jahn-Teller $\mathrm{Ni}^{3+}\left(\mathrm{d}^{7}\right)$ in the graphene-coated $\mathrm{Li}\left(\mathrm{Li}_{\text {o.2 }} \mathrm{Mn}_{\mathrm{o} .54} \mathrm{Ni}_{\mathrm{O} .13} \mathrm{Co}_{0.13}\right) \mathrm{O}_{2}$ cathode appears to be irreversible according to the visual inspection from the CCWT although the oxidation change was reversible. There was significant differences in the symmetry and intensity of the shapes on the CCWT modulus between the charge (REF 4.7507 V) and discharge (3.8513 $\mathrm{V} \sim 2.1822 \mathrm{~V}$ ) on the $\mathrm{Ni}$ atomic environment. Also, the splitting of Ni-O into the long and short Ni-O attributed to the Jahn-Teller effect was identified, and it showed the maximum bond length difference at $4.5064 \mathrm{~V}$. In this experiment, the mean-square disorder parameter $\left(\sigma^{2}\right)$ from the EXAFS Debye-Waller factor $\left(e^{-2 \sigma k^{2}}\right)$ indicates the structural disorder determined by the EXAFS fitting with the composite model of $\mathrm{xLi}_{2} \mathrm{MnO}_{3} \cdot(1-\mathrm{x}) \mathrm{LiMO}_{2}$. The fluctuation of the structural disorder $\left(\sigma^{2}\right)$ was generally higher in the 2nd shell compared with the ist shell. At $4.5064 \mathrm{~V}$, the structural disorder in Mn-TM $\left(\sigma^{2}=0.01 \AA^{2}\right)$ and $\mathrm{Ni}$ TM $\left(\sigma^{2}=0.014 \AA^{2}\right)$ reached maximum, whereas the structural disorder $\left(\sigma^{2}\right)$ in Co-TM (o.ooo $\left.4 \AA^{2}\right)$ was minimum. These results seem to be the case due to the reaction mechanism of the activated $\mathrm{Mn}$ from $\mathrm{Li}_{2} \mathrm{MnO}_{3}$ component and the process involved the migration of transition metals. However, the simultaneous activation from $\mathrm{Mn}$ and $\mathrm{Ni}$ appears to suppress the local environment change of Co-TM. This finding corresponds to the result obtained from the Co CCWT analysis at $\sim 4.5064 \mathrm{~V}$ (as the signal of the CCWT modulus of Co-TM exhibits a clear figure with reasonable symmetry even slightly better than that of the REF point. On the other side, at $\sim 4.5064 \mathrm{~V}$, the highest intensity of the CCWT modulus in Co-O and Ni-O slightly decreased, indicating higher disorder possibly because of large amount of the oxygen removal. Up on further charge-discharge, the Co-O is likely to restore its symmetry while $\mathrm{Ni}-\mathrm{O}$ reveals irreversible atomic environment changes. There were little changes in the $\mathrm{Mn}-\mathrm{O}$ environment during the ist electrochemical cycle according to the Mn K-edge CCWT analysis. The present study demonstrates a new approach into the examination of the atomic environment change during the $\mathrm{Li}^{+}$ (de)intercalation in the cathode composite. A new concept, namely, 'atomic phase reversibility' has been suggested. Phase reversibility during charge cycling of Li-ion cathode active materials is the observable forward and reverse change of the lattice structure during charging and discharging. In the present study this reversibility has been observed experimentally via the use of operando XAS analysis and EXAFS interpretation that revealed the changes in the local atomic environment of transition metal atoms. Findings from this study will contribute to the knowledge of designing improved battery electrodes.

\section{ASSOCIATED CONTENT}

\section{SUPPORTING INFORMATION}

Fitting results of EXAFS and Rietveld refinement of XRD. This material is available free of charge via the Internet at http://pubs.acs.org.

\section{AUTHOR INFORMATION}

\section{Corresponding Author}

* E-mail: taehoon.kim@oist.jp

Present Addresses

$\omega$ Qi Unit, Energy Materials and Surface Science, Okinawa Institute of Science and Technology (OIST), 1919-1 Tancha, Onnason, Okinawa, 904-0495, Japan.

$\Omega$ Materials Science and Engineering Program \& Texas Materials Institute, The University of Texas at Austin, Austin, Texas 78712, USA.

\section{Notes}

The authors declare no competing financial interest.

\section{ACKNOWLEDGMENT}

We would like to acknowledge the support for the use of the synchrotron source at the B18 Core EXAFS beamline at Diamond Light Source (DLS, UK) under the rapid access scheme with proposal number SP 4004.

\section{REFERENCES}

(1) Thackeray, M. M.; Kang, S.-H.; Johnson, C. S.; Vaughey, J. T.; Benedek, R.; Hackney, S. a. $\mathrm{Li}_{2} \mathrm{MnO}_{3}$-Stabilized $\mathrm{LiMO}_{2}(\mathrm{M}=\mathrm{Mn}, \mathrm{Ni}, \mathrm{Co})$ Electrodes for Lithium-Ion Batteries. J. Mater. Chem. 2007, 17 (30), 3112. 
(2) Goodenough, J. B.; Kim, Y. Challenges for Rechargeable Li Batteries †. Chem. Mater. 2010, 22 (3), 587-603.

(3) Deng, H.; Belharouak, I.; Cook, R. E.; Wu, H.; Sun, Y.K.; Amine, K. Nanostructured Lithium Nickel Manganese Oxides for Lithium-Ion Batteries. J. Electrochem. Soc. 2010, 157 (4), A447.

(4) Armand, M.; Tarascon, J.-M. Building Better Batteries. Nature 20o8, 451 (7179), 652-657.

(5) Arunkumar, T. A.; Wu, Y.; Manthiram, A. Factors Influencing the Irreversible Oxygen Loss and Reversible Capacity in Layered $\mathrm{Li}\left[\mathrm{Li}_{1 / 3} \mathrm{Mn}_{2 / 3}\right] \mathrm{O}_{2}-\mathrm{Li}[\mathrm{M}] \mathrm{O}_{2}\left(\mathrm{M}=\mathrm{Mn}_{0.5-\mathrm{y}} \mathrm{Ni}_{0.5-\mathrm{y}} \mathrm{Co}_{2 \mathrm{y}}\right.$ and $\mathrm{Ni}_{1-\mathrm{y}} \mathrm{Co}_{\mathrm{y}}$ ) Solid. Chem. Mater. 2007, 19 (12), 3067-3073.

(6) Amalraj, F.; Kovacheva, D.; Talianker, M.; Zeiri, L.; Grinblat, J.; Leifer, N.; Goobes, G.; Markovsky, B.; Aurbach, D. Integrated Materials xLi[sub 2] MnO[sub 3] $(1-x) \operatorname{LiMn}[$ sub 1/3] Ni[sub 1/3] Co[sub 1/3] O[sub 2] (x=0.3, o.5, o.7) Synthesized. J. Electrochem. Soc. 2010, 157 (10), A1121.

(7) Wu, Y.; Vadivel Murugan, a.; Manthiram, a. Surface Modification of High Capacity Layered Li[Li[sub o.2] Mn[sub 0.54] Ni[sub 0.13] Co[sub 0.13]]O[sub 2] Cathodes by AlPO[sub 4]. J. Electrochem. Soc. 2008, 155 (9), A635.

(8) Johnson, C. S.; Kim, J.-S.; Lefief, C.; Li, N.; Vaughey, J. T.; Thackeray, M. M. The Significance of the $\mathrm{Li}_{2} \mathrm{MnO}_{3}$ Component in "composite" xLi2 $\mathrm{MnO}_{3} \cdot(1-\mathrm{x}) \mathrm{LiMno} .{ }_{5} \mathrm{Nio}_{5} \mathrm{O}_{2}$ Electrodes. Electrochem. commun. 2004, 6 (10), 1085-1091.

(9) Kang, S.-H.; Sun, Y. K.; Amine, K. Electrochemical and Ex Situ X-Ray Study of $\mathrm{Li}\left(\mathrm{Li}_{\mathrm{O}_{2}} \mathrm{Ni}_{\mathrm{o} .2} \mathrm{Mn}_{0.6}\right) \mathrm{O}_{2}$ Cathode Material for Li Secondary Batteries. Electrochem. Solid-State Lett. 2003, 6 (9), A183.

(10) Kim, G. Y.; Yi, S. B.; Park, Y. J.; Kim, H. G. Electrochemical Behaviors of $\mathrm{Li}[\mathrm{Li}(1-\mathrm{x}) / 3 \mathrm{Mn}(2-$ $\mathrm{x}) / 3 \mathrm{Nix} / 3 \mathrm{Cox} / 3 \mathrm{~J} \mathrm{O}_{2}$ Cathode Series $(\mathrm{o}<\mathrm{X}<1)$ Synthesized by Sucrose Combustion Process for High Capacity Lithium Ion Batteries. Mater. Res. Bull. 2oo8, 43 (12), 3543-3552.

(11) Armstrong, R.; Holzapfel, M.; Novák, P.; Johnson, C. S.; Kang, S. H.; Thackeray, M. M.; Bruce, P. G. Demonstrating Oxygen Loss and Associated Structural Reorganization in the Lithium Battery Cathode $\mathrm{Li}\left[\mathrm{Ni}_{0.2} \mathrm{Li}_{0.2} \mathrm{Mn}_{0.6}\right] \mathrm{O}_{2}$. J. Am. Chem. Soc. 2006, 128 (26), 8694-8698.

(12) Lu, Z.; Beaulieu, L. Y.; Donaberger, R. a.; Thomas, C. L.; Dahn, J. R. Synthesis, Structure, and Electrochemical Behavior of $\mathrm{Li}\left[\mathrm{Ni}_{\mathrm{x}} \mathrm{Li}_{1 / 3-2 \mathrm{x} / 3} \mathrm{Mn}_{2 / 3-\mathrm{x} / 3} \mathrm{O}_{2}\right.$. J. Electrochem. Soc. 2002, 149 (6), A778.

(13) Armstrong, A. R.; Robertson, A. D.; Bruce, P. G. Overcharging Manganese Oxides: Extracting Lithium beyond $\mathrm{Mn}^{4+}$. J. Power Sources 2005, 146 (1-2), 275-280.

(14) Lu, Z.; Dahn, J. R. Understanding the Anomalous Capacity of $\mathrm{Li} / \mathrm{Li}\left[\mathrm{Ni}_{\mathrm{x}} \mathrm{Li}_{(1 / 3-2 \mathrm{x} / 3)}\right] \mathrm{Mn}_{(2 / 3-\mathrm{x} / 3)} \mathrm{O}_{2}$ Cells Using In Situ XRay Diffraction and Electrochemical Studies. J. Electrochem. Soc. 2002, 149 (7), A815.

(15) Mohanty, D.; Kalnaus, S.; Meisner, R. a.; Rhodes, K. J.; Li, J.; Payzant, E. A.; Wood, D. L.; Daniel, C. Structural Transformation of a Lithium-Rich Li1.2Coo.1Mno. ${ }_{55} \mathrm{Nio.}_{15} \mathrm{O}_{2}$ Cathode during High Voltage Cycling Resolved by in Situ X-Ray Diffraction. J. Power Sources 2013, 229, 239-248.

(16) Yabuuchi, N.; Yoshii, K.; Myung, S.-T.; Nakai, I.; Komaba, S. Detailed Studies of a High-Capacity Electrode Material for Rechargeable Batteries, $\mathrm{Li}_{2} \mathrm{MnO}_{3}-\mathrm{LiCo}_{1 / 3} \mathrm{Ni}_{1 / 3} \mathrm{Mn}$ $1 / 3 \mathrm{O}_{2}$. J. Am. Chem. Soc. 2011, 133 (12), 4404-4419.

(17) Li, H. H.; Yabuuchi, N.; Meng, Y. S.; Kumar, S.; Breger, J.; Grey, C. P.; Shao-Horn, Y. Changes in the Cation Ordering of Layered $\mathrm{O}_{3}$ LixNio.5Mno.5 $\mathrm{O}_{2}$ during Electrochemical Cycling to
High Voltages: An Electron Diffraction Study. Chem. Mater. 2007, 19 (10), 2551-2565.

(18) Thackeray, M. M.; Kang, S.-H.; Johnson, C. S.; Vaughey, J. T.; Hackney, S. A. Comments on the Structural Complexity of Lithium-Rich $\mathrm{Li}_{1+\mathrm{x}} \mathrm{M}_{1-\mathrm{x}} \mathrm{O}_{2}$ Electrodes $(\mathrm{M}=\mathrm{Mn}, \mathrm{Ni}$, Co) for Lithium Batteries. Electrochem. commun. 2006, 8 (9), 1531-1538.

(19) Kim, J.; Johnson, C. S.; Vaughey, J. T.; Thackeray, M. M.; Hackney, S. A.; Grey, C. P. Electrochemical and Structural Properties of Batteries ( $\mathrm{M}^{\prime}$ ) Ti , Mn , Zr ; o E X E o . 3 ). 2oo6, No. 9, 1996-2006.

(20) Yoon, W.; Iannopollo, S.; Grey, C. P.; Carlier, D.; Gorman, J.; Reed, J.; Ceder, G. Local Structure and Cation Ordering in $\mathrm{O}_{3}$ Lithium Nickel Manganese Oxides with Stoichiometry. 2004, 167-171.

(21) Song, B.; Lai, M. O.; Lu, L. Influence of Ru Substitution on Li-Rich $0.55 \mathrm{Li}_{2} \mathrm{MnO}_{3} \cdot 0.45 \mathrm{LiNi}_{1 / 3} \mathrm{Co}_{1 / 3} \mathrm{Mn}_{1 / 3} \mathrm{O}_{2}$ Cathode for LiIon Batteries. Electrochim. Acta 2012, 80, 187-195.

(22) Gao, J.; Manthiram, a. Eliminating the Irreversible Capacity Loss of High Capacity Layered Li[Lio.2Mno.54Nio.13Coo.13] O2 Cathode by Blending with Other Lithium Insertion Hosts. J. Power Sources 20o9, 191 (2), 644-647.

(23) Song, B.; Liu, Z.; Lai, M. O.; Lu, L. Structural Evolution and the Capacity Fade Mechanism upon Long-Term Cycling in Li-Rich Cathode Material. Phys. Chem. Chem. Phys. 2012, 14 (37), 12875 .

(24) He, W.; Qian, J.; Cao, Y.; Ai, X.; Yang, H. Improved Electrochemical Performances of Nanocrystalline Li[Lio.2Mno.54Nio.13Coo.13]O2 Cathode Material for Li-Ion Batteries. RSC Adv. 2012, 2 (8), 3423.

(25) Zheng, J. M.; Wu, X. B.; Yang, Y. A Comparison of Preparation Method on the Electrochemical Performance of Cathode Material Li[Lio.2Mno.54Nio.13Coo.13]O2 for Lithium Ion Battery. Electrochim. Acta 2011, 56 (8), 3071-3078.

(26) He, Z.; Wang, Z.; Guo, H.; Li, X.; Xianwen, W.; Yue, P.; Wang, J. A Simple Method of Preparing Graphene-Coated Li[Lio.2Mno.54Nio.13Coo.13] O2 for Lithium-Ion Batteries. Mater. Lett. 2013, 91, 261-264.

(27) McBreen, J. The Application of Synchrotron Techniques to the Study of Lithium-Ion Batteries. J. Solid State Electrochem. 2008, 13 (7), 1051-1061.

(28) Ni, L.; Co, L. In Situ X-Ray Absorption Spectroscopic Study of Li-Rich Layered Cathode Material. J. Power Sources 2011, 196 (16), 6828-6834.

(29) Croy, J. R.; Balasubramanian, M.; Kim, D.; Kang, S.-H.; Thackeray, M. M. Designing High-Capacity, Lithium-Ion Cathodes Using X-Ray Absorption Spectroscopy. Chem. Mater. 2011, 23 (24), 5415-5424.

(30) Simonin, L.; Colin, J.-F.; Ranieri, V.; Canévet, E.; Martin, J.-F.; Bourbon, C.; Baehtz, C.; Strobel, P.; Daniel, L.; Patoux, S. In Situ Investigations of a Li-Rich Mn-Ni Layered Oxide for Li-Ion Batteries. J. Mater. Chem. 2012, 22 (22), 11316.

(31) Croy, J. R.; Gallagher, K. G.; Balasubramanian, M.; Chen, Z.; Ren, Y.; Kim, D.; Kang, S.-H.; Dees, D. W.; Thackeray, M. M. Examining Hysteresis in Composite $x \mathrm{Li}_{2} \mathrm{MnO}_{3} \cdot(1-x$ $\mathrm{LiMO}_{2}$ Cathode Structures. J. Phys. Chem. C 2013, 117 (13), 65256536.

(32) Oishi, M.; Fujimoto, T.; Takanashi, Y.; Orikasa, Y.; Kawamura, A.; Ina, T.; Yamashige, H.; Takamatsu, D.; Sato, K.; Murayama, H.; Tanida, H.; Arai, H.; Ishii, H.; Yogi, C.; Watanabe, I.; Ohta, T.; Mineshige, A.; Uchimoto, Y.; Ogumi, Z. Charge 
Compensation Mechanisms in $\mathrm{Li}_{1.16} \mathrm{Ni}_{\text {o.15 }} \mathrm{Co}_{0.19} \mathrm{Mn}_{0.50} \mathrm{O}_{2}$ Positive Electrode Material for Li-Ion Batteries Analyzed by a Combination of Hard and Soft X-Ray Absorption near Edge Structure. J. Power Sources 2013, 222, 45-51.

(33) Uñoz, M. A. M.; Rgoul, P. I. A.; Arges, F. R. F. Continuous Cauchy Wavelet Transform Analyses of EXAFS Spectra : A Qualitative Approach. Am. Mineral. 2003, 88, 694700.

(34) Su, F.-Y.; He, Y.-B.; Li, B.; Chen, X.-C.; You, C.-H.; Wei, W.; Lv, W.; Yang, Q.-H.; Kang, F. Could Graphene Construct an Effective Conducting Network in a High-Power Lithium Ion Battery? Nano Energy 2012, 1 (3), 429-439.

(35) Kim, H.; Seo, D.-H.; Kim, S.-W.; Kim, J.; Kang, K. Highly Reversible $\mathrm{Co}_{3} \mathrm{O}_{4}$ /graphene Hybrid Anode for Lithium Rechargeable Batteries. Carbon N. Y. 2011, 49 (1), 326-332.

(36) Song, B.; Lai, M. O.; Liu, Z.; Liu, H.; Lu, L. GrapheneBased Surface Modification on Layered Li-Rich Cathode for High-Performance Li-Ion Batteries. J. Mater. Chem. A 2013, 1 (34), 9954-9965.

(37) Mai, Y. J.; Zhang, D.; Qiao, Y. Q.; Gu, C. D.; Wang, X. L.; Tu, J. P. MnO/reduced Graphene Oxide Sheet Hybrid as an Anode for Li-Ion Batteries with Enhanced Lithium Storage Performance. J. Power Sources 2012, 216, 201-207.

(38) Chen, L.; Zhang, M.; Wei, W. Graphene-Based Composites as Cathode Materials for Lithium Ion Batteries. J. Nanomater. 2013, 2013, 1-8.

(39) Persson, K.; Sethuraman, V. A.; Hardwick, L. J.; Hinuma, Y.; Meng, Y. S.; van der Ven, A.; Srinivasan, V.; Kostecki, R.; Ceder, G. Lithium Diffusion in Graphitic Carbon. J. Phys. Chem. Lett. 2010, 1 (8), 1176-1180.

(40) Deb, a; Bergmann, U.; Cramer, S. P.; Cairns, E. J. In Situ X-Ray Absorption Spectroscopic Study of the $\mathrm{Li}[\mathrm{Ni} 1 / 3 \mathrm{Co} 1 / 3 \mathrm{Mn} 1 / 3] \mathrm{O}-2$ Cathode Material. J. Appl. Phys. 2005, 97 (11).

(41) Gorlin, Y.; Siebel, A.; Piana, M.; Huthwelker, T.; Jha, H.; Monsch, G.; Kraus, F.; Gasteiger, H. A.; Tromp, M. Operando Characterization of Intermediates Produced in a Lithium-Sulfur Battery. J. Electrochem. Soc. 2015, 162 (7), A1146-A1155.

(42) Wang, J.; Chen-Wiegart, Y. K.; Wang, J. Operando Tracking Phase Transformation Evolution of Lithium Iron Phosphate with Hard X-Ray Microscopy. Nat. Commun. 2014, 5, 4570.

(43) Ravel, B.; Newville, M. ATHENA, ARTEMIS, HEPHAESTUS: Data Analysis for X-Ray Absorption Spectroscopy Using IFEFFIT. J. Synchrotron Radiat. 2005, 12 (4), 537-541.

(44) Huang, Z.-F.; Du, F.; Wang, C.-Z.; Wang, D.-P.; Chen, G. Low-Spin Mn3+ Ion in Rhombohedral LiMnO2 Predicted by First-Principles Calculations. Phys. Rev. B 2007, 75 (5), 054411.

(45) Prasad, R.; Benedek, R.; Kropf, A.; Johnson, C.; Robertson, A.; Bruce, P.; Thackeray, M. Divalent-Dopant Criterion for the Suppression of Jahn-Teller Distortion in Mn Oxides - First-Principles Calculations and X-Ray Absorption Spectroscopy Measurements for Co in LiMnO2. Phys. Rev. B 2003, 68 (1), 012101.

(46) Rumble, C.; Conry, T. E.; Doeff, M.; Cairns, E. J.; Penner-Hahn, J. E.; Deb, A. Structural and Electrochemical Investigation of $\mathrm{Li}(\mathrm{Ni}[$ sub 0.4 ] $\mathrm{Co}$ [sub 0.15] Al[sub o.05] Mn[sub o.4])O[sub 2] Cathode Material. J. Electrochem. Soc. 2010, 157 (12), A1317.
(47) Li, Z.; Chernova, N. a.; Roppolo, M.; Upreti, S.; Petersburg, C.; Alamgir, F. M.; Whittingham, M. S. Comparative Study of the Capacity and Rate Capability of LiNiyMnyCo1-2yO2 $(\mathrm{y}=0.5,0.45,0.4,0.33)$. J. Electrochem. Soc. 2011, 158 (5), A516.

(48) Yu, X.; Lyu, Y.; Gu, L.; Wu, H.; Bak, S.-M.; Zhou, Y.; Amine, K.; Ehrlich, S. N.; Li, H.; Nam, K.-W.; Yang, X.-Q. Understanding the Rate Capability of High-Energy-Density LiRich Layered Li 1.2 Ni o.15 Co o.1 Mn 0.55 O 2 Cathode Materials. Adv. Energy Mater. 2014, 4 (5), n/a - n/a.

(49) Yu, X.; Lyu, Y.; Gu, L.; Wu, H.; Bak, S. M.; Zhou, Y.; Amine, K.; Ehrlich, S. N.; Li, H.; Nam, K. W.; Yang, X. Q. Understanding the Rate Capability of High-Energy-Density LiRich Layered Li1.2Nio.15Coo.1Mno.55O2 Cathode Materials. Adv. Energy Mater. 2014, 4 (5), 1-11.

(50) Croy, J. R.; Gallagher, K. G.; Balasubramanian, M.; Long, B. R.; Thackeray, M. M. Quantifying Hysteresis and Voltage Fade in $\mathrm{xLi}_{2} \mathrm{MnO}_{3}$ bullet(1-x)LiMno.5Nio.5O2 Electrodes as a Function of $\mathrm{Li}_{2} \mathrm{MnO}_{3}$ Content. J. Electrochem. Soc. 2013, 161 (3), A318-A325.

(51) Bareno, J.; Balasubramanian, M.; Kang, S. H.; Wen, J. G.; Lei, C. H.; Pol, S. V.; Petrov, I.; Abraham, D. P. Long-Range and Local Structure in the Layered Oxide Li1.2Co o.4Mno.4O2. Chem. Mater. 2011, 23 (8), 2039-2050.

(52) Jing, C.; Liu, S.; Patel, M.; Meng, X. Arsenic Leachability in Water Treatment Adsorbents. Environ. Sci. Technol. 2005, 39 (14), 5481-5487.

(53) Harfouche, M.; Labanowski, J.; Farges, F.; Hullebusch, E. Van; Borca, C.; Grolimund, D.; Oort, F. Van. Assessment of Zn Bioavailability: XAFS Study on Speciation of Zinc-Particulate Organic Matter Associations in Polluted Soils. J. Phys. Conf. Ser. 2009, 190, 012189.

(54) Sayers, D. E.; Stern, E. a.; Lytle, F. W. New Technique for Investigating Noncrystalline Structures: Fourier Analysis of the Extended X-Ray-Absorption Fine Structure. Phys. Rev. Lett. 1971, 27 (18), 1204-1207.

(55) Rehr, J. J. Theoretical Approaches to X-Ray Absorption Fine Structure. Rev. Mod. Phys. 2ooo, 72 (3), 621-654.

(56) Muoz, M.; Farges, F.; Argoul, P. Continuous Cauchy Wavelet Transform of XAFS Spectra. Phys. Scr. 2005, $2005,221$. 


\section{Abstract graphic}

\section{Atomic environment}

(Large) $\mathrm{Li}^{+} / \mathrm{Ni}^{2+}$

- (Small) $\mathrm{Co}^{3+} / \mathrm{Mn}^{4+}$
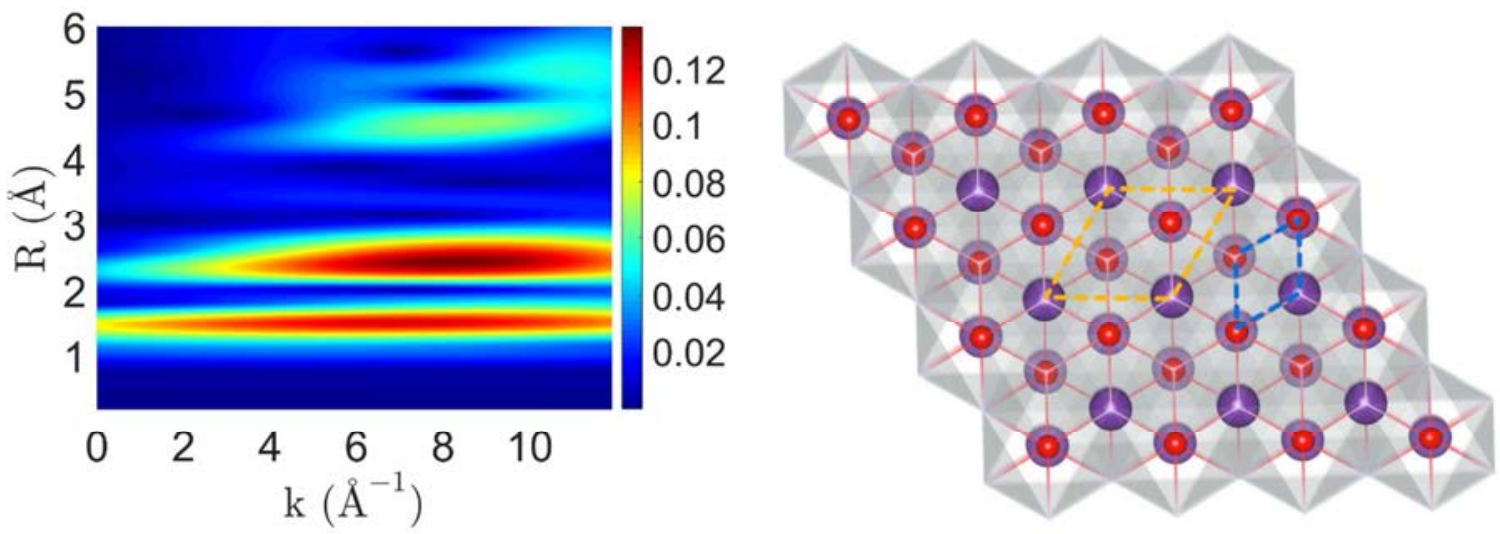


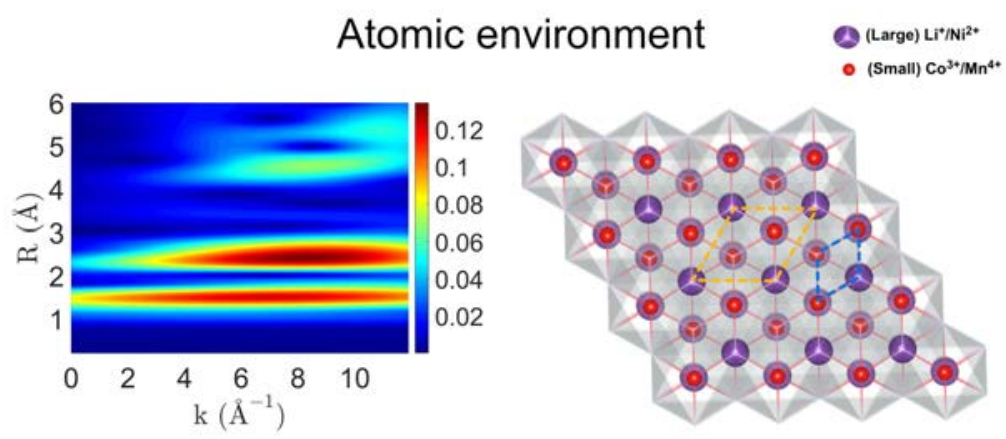

